\title{
Systematic profiling of SARS-CoV-2 specific IgG epitopes at single amino acid resolution
}

Huan $\mathrm{Qi}^{1,+}$, Ming-liang Ma ${ }^{1,+}$, He-wei Jiang ${ }^{1,+}$, Jian-ya Ling ${ }^{2,+}$, Ling-yun Chen ${ }^{3,4,+}$, Hai-nan Zhang ${ }^{1}$, Dan-yun $\mathrm{Lai}^{1}$, Yang $\mathrm{Li}^{1}$, Zi-wen Guo ${ }^{5}$, Chuan-sheng $\mathrm{Hu}^{5}$, Shu-Juan Guo $^{1}$, Qing-feng Meng ${ }^{1}$, Yan Ren ${ }^{3}$, Wei Wang ${ }^{6}$, Xiao Yang ${ }^{7}$, Jie Zhou ${ }^{6, *}$, Xiao-dong $\mathrm{Zhao}^{1,{ }^{*}, \text { Hua } \mathrm{Li}^{5,}, \text {, Sheng-ce Tao }}{ }^{1, *}$

${ }^{1}$ Shanghai Center for Systems Biomedicine, Key Laboratory of Systems Biomedicine (Ministry of Education), Shanghai Jiao Tong University, Shanghai, 200240, China

${ }^{2}$ State Key Laboratory of Microbial Technology, Shandong University, Qingdao, Shandong, 266237, China

${ }^{3}$ BGI-Shenzhen, Shenzhen, Guangdong, 518083, China

${ }^{4}$ BGI Education Center, University of Chinese Academy of Sciences, Shenzhen, Guangdong, 518083, China

${ }^{5}$ State Key laboratory for Oncogenes and Bio-ID Center, School of Biomedical Engineering, Shanghai Jiao Tong University, Shanghai, 200240, China

${ }^{6}$ Foshan Fourth People's Hospital, Foshan, Guangdong, 528000, China

${ }^{7}$ Institute of Biophysics, Chinese Academy of Sciences, Beijing, 100101, China

${ }^{+}$These authors contributed equally

*Corresponding Authors, e-mail: taosc@ @stu.edu.cn (S.-c. T.), kaikaixinxin@ @stu.edu.cn (H. L.), xiaodongzhao@sjtu.edu.cn (X.-d. Z.), zjet65@163.com (J. Z.) 


\begin{abstract}
SARS-CoV-2 specific IgG responses play critical roles for patients to recover from COVID-19, in-depth dissecting of the IgG responses on systems level is of great interest. Herein, we adopted a newly developed high-throughput epitope mapping technology (AbMap), analyzed 55 COVID-19 convalescent sera and 226 antibody samples enriched by specific proteins or peptides from these sera. We revealed three areas that are rich of IgG epitopes, two are on Spike protein but outside of RBD, and one is on Nucleocapsid protein. We identified 29 significant epitopes on Spike protein, from two of these significant epitopes, two critical epitope residues were found, i. e., D936 and P1263, which are highly related to the infectivity of SARS-CoV-2. In summary, we provided the first global map of IgG binding epitopes for SARS-CoV-2 at single amino acid resolution. This map will facilitate the precise development of therapeutic antibodies and vaccines.
\end{abstract}

\title{
KEYWORDS
}

COVID-19, SARS-CoV-2, IgG, epitope mapping, AbMap

\section{HIGHLIGHTS}

1. A map of SARS-CoV-2 specific IgG binding epitopes at single amino acid resolution

2. Two areas outside of RBD that are rich of significant epitopes were identified

3. One area rich of significant epitopes was determined on Nucleocapsid protein

4. Two critical epitope residues (D936 and P1263) on Spike protein are highly related to the infectivity of SARS-CoV-2 


\section{INTRODUCTION}

COVID-19 is a worldwide pandemic and caused by SARS-CoV-2 (1, 2). By September 8, 2020, 27,249,308 cases were diagnosed and 890,971 lives were claimed (https://coronavirus.jhu.edu/map.html) (3). Vaccines and therapeutic antibodies of high effectivity are desperately needed. It is known that SARS-CoV-2 encodes 27 proteins, of these proteins, Spike protein (S protein) plays a critical role in the specific binding of SARS-CoV-2 to human cells. During the infection, specific proteases cut S protein at S2' and furin site to split S1 and S2 (4). S protein is rich of N-glycosylation, i. e., 21 sites (5). On $\mathrm{S}$ protein, RBD domain is presently the central target to develop SARS-CoV-2 antibodies and vaccines (6-10). Other areas of S protein can also elicit B cell responses and neutralization antibodies (11-15). Nucleocapsid protein ( $\mathrm{N}$ protein) is highly abundant and triggers significant IgG response (16-18).

SARS-CoV-2 specific IgG response is critical for the recovery of COVID-19 patient, since specific and effective therapy is still not available. The comprehensive and in-depth revealing of SARS-CoV-2 specific IgG responses will definitely help us to understand the COVID-19 immunity better, and to facilitate the precise development of neutralization antibodies and vaccines. To reveal the SARS-CoV-2 specific IgG response, several studies have been performed through different angles by applying different strategies. By analyzing 55 convalescent sera on a SARS-CoV-2 proteome microarray, the IgG responses against 18 SARS-CoV-2 proteins were surveyed, including S1, S2, N and RBD (16). By analyzing sera from 1,051 patients on a $\mathrm{S}$ protein peptide microarray of full S protein coverage, several areas and a set of peptides of high IgG reactivity were identified (14). Similar studies were also performed by using another peptide microarray (17), and a coronavirus specific phage displayed peptide library (19). The IgG responses on protein and peptide levels, but not single amino acid level, were at least partially revealed by these studies.

Herein, we aimed to go one step further to dissect the SARS-CoV-2 specific IgG responses systematically at single amino acid level. We adopted AbMap, a method that was developed recently (20) for high-throughput epitope mapping. A set of 55 convalescent sera and 226 samples of protein/ peptide enriched antibodies from these sera 
were analyzed. A map of SARS-CoV-2 specific IgG epitopes at single amino acid resolution was generated for the first time.

\section{RESULTS}

\section{Schematic diagram: an epitope mapping strategy with three layers of samples}

To globally profile the IgG binding epitopes on SARS-CoV-2 proteins from COVID-19 sera, we collected sera from 55 convalescent patients, and 25 controls. The patients were hospitalized in Foshan Fourth hospital in China from 2020-1-25 to 2020-3-8 for various durations. Patient information is summarized in Table S1. Serum from each patient was collected on the day of hospital discharge when standard criteria were met.

It is known that serum is rich of antibodies $(7,21)$, and it is reasonable to argue that SARS-CoV-2 specific IgGs will compose only a small portion of the total IgGs in serum. In order to increase the signal to noise ratio of the following-up epitope mapping, the sera from the 55 convalescent patients were subjected for antibody enrichment by specific SARS-CoV-2 proteins and peptides. The three layers of samples, $i$. e., the serum, the protein enriched antibodies, and the peptide enriched antibodies were then subjected for IgG binding epitope mapping by AbMap, a technology that we have established recently (20). Statistically significant epitopes were successfully identified for all these three layers of samples (Fig. 1). A variety of epitopes identified from the protein and peptide enriched antibodies could be matched to the sequence of the corresponding proteins and peptides. These results indicate AbMap is suitable for dissecting the SARS-CoV-2 IgG binding epitopes using COVID-19 sera as input.

\section{A map of SARS-CoV-2 specific IgG binding epitopes}

To reveal the epitopes at systems level, the 55 convalescent sera were subjected for AbMap analysis directly, following the procedure that we established recently (20) and used a high stringent cutoff, we have identified 418 motifs (Table S2), 275 of which could be matched to 27 of the 28 known SARS-CoV-2 proteins (Table S3, Fig. 2A), we recognized these motifs as epitopes of high confidence. Vertically (Fig. 2A), to estimate 
the variation of SARS-CoV-2 specific IgG responses among the 55 convalescent sera, we added up the epitope frequency for each patient. The results clearly showed that there are significant differences among the patients, with a frequency from 0 to 27 . According to the histogram of the frequency (Fig. 2B), we noticed that the number of patients is inversely proportional to the frequency, this suggest the SARS-CoV-2 specific $\operatorname{IgG}$ response is not randomly distributed among the patients, the underlying mechanism may be worth further exploration. Horizontally (Fig. 2A), to check the distribution of the epitopes among the proteins, we also counted the epitopes for each protein, $i$. $e$., sum_epitopes. There are big variations of the sum_epitopes from 0 for ORF6 to 125 for NSP3 (Fig. 2C). Since the size of the 28 SARS-CoV-2 proteins varied a lot from 22 aa (ORF3b) to 1,945 aa (NSP3), it is possible that the variations of the sum_epitopes may be due to the different sizes of the proteins. To check this possibility, we divided sum_epitopes by the length of the proteins, indeed, the variation of the sum_epitopes among protein was largely normalized. However, there are still significant variations for sum_epitopes/ length among the proteins, from 0 for ORF6 to 0.08 for NSP9, these differences may be due to the accessibility of these proteins to the immune system during infection, further study may be needed to address this.

Except the SARS-CoV-2 specific antibodies, there are many other antibodies in the convalescent sera, it is possible that a big portion of the 143 un-matched motifs may correspond to the un-related antibodies (22). To reveal more SARS-CoV-2 epitopes of high confidence, it is necessary to improve the signal-to-noise ratio of AbMap. For this purpose, we decided to enrich protein specific antibodies for AbMap. According to one of our previous study (16), we knew N protein, S1, S2 and RBD are of high reactivity among patients. Because we only had very limited amount of sera, we decided to enrich the antibodies from each sample in a consequential manner, i. e., RBD, S1, S2 and N. To ensure the quality of the enrichment, proteins that biotinylated through Avi-tag and streptavidin coated magnetic beads were adopted (Fig. S1). Clearly, a variety of highly confident epitopes were identified and could be matched to the sequences of the corresponding proteins (Table S3). 
Thus, we generated a map of SARS-CoV-2 specific IgG binding epitopes by analyzing 55 convalescent sera and 226 samples of antibodies enriched by specific proteins from these sera.

\section{Two areas outside of RBD that rich of significant epitopes were identified on Spike protein}

$\mathrm{S}$ protein is the key protein for infection and is known to be highly immunogenic $(15,16)$. To present the distribution of the epitopes on S protein, we merged the sequence matched epitopes revealed from both S1 and S2 enriched antibodies (Table S3). When matching the epitopes to $\mathrm{S}$ protein sequence, if an epitope sequence obtained from one sample is the same for other samples, we counted this epitope as 1 for this sample and added it up for all the samples as the final frequency of this epitope. We then plotted the epitopes, the epitopes sequences, and the frequencies alongside the linear sequence and domains of $S$ protein (Fig. 3A). The results clearly showed that the epitopes are distributed cross but not evenly on $\mathrm{S}$ protein. Two hot areas that rich of significant epitopes were readily identified, the first area almost covers the entire CTD (C terminal domain), the second area covers the S2' protease cleavage site and the fusion peptide (FP). Significant epitopes were also identified on the cytoplasmic C-terminal end of S protein. These results are highly consistent to a peptide microarray-based study, of which about 4,000 samples were analyzed against a set of 197 peptides that covers the entire S protein (14, 15).

It is interesting to test the necessity of enriching SARS-CoV-2 specific antibodies from sera. To this end, we took $\mathrm{S}$ protein as an example, we plotted the epitopes identified by using serum directly (Fig. S2 black dots) and the S protein enriched antibodies (Fig. S2 red dots) alongside the sequence of $\mathrm{S}$ protein. The distributions are similar between sera and $\mathrm{S}$ protein enriched antibodies, as expected, many more significant epitopes with higher frequency were identified by using the $\mathrm{S}$ protein enriched antibodies (Fig. S2). This improvement may be due to the removal of unrelated antibodies from sera, thus the signal-to-noise ratio was significantly enhanced. 
We defined the epitopes with frequency $>=3$ as significant epitopes and obtained 28 of them (Fig. S3A). To further illustrate the location and distribution of the 28 significant epitopes (Fig. S3A), we mapped them to the 3D structure of Spike protein (23) monomer (Fig. 3B) and trimer (Fig. S3B). It is clear that most of these epitopes locate on the surface of Spike protein, which is consistent to the common notion (24). However, Epitope-S1-6 (KCVNFNFN) and Epitope-S2-3 (QEVFAQVK) are not on the surface of the trimeric Spike protein, but on the surface of the monomer. A plausible explanation is that specific areas of the Spike protein monomer could be exposed to the immune system during the infection. To further pinpoint the locations of the critical residues of the significant epitopes, we took 4 critical epitope residues, i. e., K558, P561, Q563 and Q564 from a significant epitope as examples (Fig. 3C). As expected, all these residues locate on the surface of S protein (Fig. 3D). To check the similarity of the epitopes/ critical epitope residues among human coronaviruses, we performed homology analysis for Epitope-S1-8 (KFLPFQQF) (Fig. S3A). High homologies were observed among SARS-Cov-2, SARS-CoV and BtCoV-RaTG13 (Fig. 3E).

Structure analysis and homology analysis were also performed for all the rest 27 significant epitopes wherever applicable (Table S4). Similar to that of Epitope-S1-8 (KFLPFQQF), most of the critical epitopes of these 27 significant epitopes also locate on the surface of $\mathrm{S}$ protein. High homologies were also observed among SARS-Cov-2, SARS-CoV and BtCoV-RaTG13 for most of the epitopes. In addition, an epitope of high homology among BtCoV-RaTG13, the three deadly human coronaviruses (SARS-CoV-2, SARS-CoV and MERS-CoV) and four common human coronaviruses (HCoV-OC43, HKU1, NL63 and 229E) was also identified, i. e., FxxELxxY (Table S4).

These results indicate that the critical epitope residues of the significant epitopes are unevenly distributed on S protein both linearly and conformationally. And the critical epitope residues are highly homologous among the 7 human coronaviruses, especially between SARS-CoV-2 and SARS-CoV.

Critical epitope residues related to the binding of Spike protein and ACE2/ neutralization antibodies, and the infectivity of SARS-CoV-2 were revealed 
Because the central role that RBD plays in binding of SARS-CoV-2 to the host cell, biotinylated RBD was also applied to enrich specific antibodies from COVID-19 convalescent sera (Fig. S1). One relative significant epitope was identified (Fig. 4A). This epitope is also consistent to our peptide microarray-based study (14). To visualize the conformational location of this epitope, we mapped the critical epitope residues (yellow), i. e., R466, D467, I468, S469, E471 and E473 to the 3D structure of RBD (25)

(Fig. 4B). It is clear that the critical epitope residues are not on the exact binding interface of RBD and ACE2 but adjacent (Fig. 4C). To further investigate whether these critical residues interference with the binding of neutralization antibodies to RBD, we studied the co-crystal structures of RBD bound by several well-studied neutralization antibodies, i. e., CR3022-Fab (8) (Fig. 4D), S309-Fv (26) (Fig. 4E), P2B-2F6-Fab (27) (Fig. S4A), BD23-Fab (7) (Fig. S4B), and CB6-Fab (28) (Fig. S4C). Interestingly, the critical residues are also not on the exact binding interface of RBD and these neutralization antibodies but adjacent. The antibodies targeting this epitope may cause conformational change or providing spatial hinderance, and thus interference the binding of ACE2 and these neutralization antibodies to RBD.

Some of the epitopes and the critical epitope residues may be related to the proper function of $S$ protein and the infectivity of SARS-CoV-2. A recent study surveyed the functional roles of a variety of SARS-CoV-2 S protein mutants, and identified a set of point mutations that cause significant reduction of the infectivity (29). To explore the roles of the critical epitope residues, we matched the mutation sites with the epitope map of S protein (Fig. 3A), we found three mutation sites are also critical epitope residues, $i$. e., H49Y, D936Y and P1263L. Except H49Y, D936Y and P1263L could cause 60-70\% and 98-99\% infectivity loss, respectively. This strongly suggest that D936 and P1263 are critical for maintaining the proper activity of S protein. According to the 2019 Novel Coronavirus Resource (2019nCoVR) database of China National Center for Bioinformation (CNCB) (https://bigd.big.ac.cn/ncov/), those three mutation sites are also of high frequency (Fig. S4D). Taken together, it is reasonable to argue that D936 and P1263 may could serve as very promising targets for neutralization antibody and vaccine development. 


\section{One area rich of significant epitopes was determined on Nucleocapsid protein}

$\mathrm{N}$ protein is highly abundant $(30,31)$ and triggers profound $\mathrm{IgG}$ response in COVID-19 patients $(18,32)$. To present the distribution of the epitopes on $\mathrm{N}$ protein, we matched the epitopes to $\mathrm{N}$ protein sequence. Following the same procedure as that of $\mathrm{S}$ protein (Fig. 3A), we calculated the frequency of each epitope, and plotted the epitopes, the epitopes sequences, and the frequencies alongside the linear sequence and domains of $\mathrm{N}$ protein. The results clearly showed that the epitopes are distributed cross but not evenly on $\mathrm{N}$ protein. One hot area rich of significant epitopes were readily identified (Fig. 5A), and 6 significant epitopes were identified when set the cutoff as frequency $>=3$ (Fig. 5B). Because the intact 3D structure of $\mathrm{N}$ protein is still not available, we thus decided only to perform homology analysis for $\mathrm{N}$ protein. High homologies for the epitopes and the critical epitope residues were observed among SARS-Cov-2, SARS-CoV and BtCoV-RaTG13 for all the 6 significant epitopes (Fig. 5C).

\section{Significant epitopes were validated by alanine scanning using a peptide microarray}

To validate the key residues of the significant epitopes, according to the frequency and the critical role of RBD, we selected four epitopes, i. e., Epitope-S1-8 (KFLPFQQF) and Epitope-S1-12 (LTPTWRVY), which are of the highest frequency, Epitope-RBD-1 (RDISTEIY) from RBD, and an epitope of low frequency, i. e., Epitope-S2-15 (KGVKLHYT) was included as control. We then mutated the amino acids of these epitopes one by one to alanine, synthesized the mutated peptides, conjugated to BSA, and fabricated a peptide microarray (Fig. S6). To validate the epitopes on the peptide microarray, we selected 5 sera, from which at least one of the significant epitopes among Epitope-S1-8 (KFLPFQQF), Epitope-S1-12 (LTPTWRVY) and Epitope-RBD-1 (RDISTEIY) was identified by AbMap (Fig. 6A). The selected sera were then probed on the peptide microarray. For all the three epitopes, when the corresponding samples were tested, significant binding signal loss was observed when any of the critical residue was 
mutated to alanine. For example, for P44 and Epitope-S1-8 (KFLPFQQF), when any of the four critical residues was mutated, the signal was almost completely lost (Fig. 6B). As expected, this is not the case for the unrelated samples (Fig. 6B, black caption). However, the binding intensities varied significantly among samples and epitopes.

It is interesting to see whether the enrichment of SARS-CoV-2 specific antibodies by proteins will enhance the specificity and signal intensity, when probed on the peptide microarray. To test this, we chose Epitope-S1-8 (KFLPFQQF) as an example, probed sera and the corresponding S1 enriched antibodies side by side. As demonstrated in Fig. S5, specific bindings were obtained for all the samples. And as expected, the antibody enrichment procedure could significantly enhance both the specificity and the signal intensity. These results further confirmed the necessity for the enrichment of antibodies from sera by specific proteins for epitope mapping.

Taken together, by combining alanine scanning and peptide microarray, the significant epitopes and critical epitope residues could be effectively validated in a fast way.

\section{DISCUSSION}

The aim of this study is to promote our understanding of SARS-CoV-2 specific IgG response in a more precise way. We adopted AbMap technology (20), analyzed 55 sera and 226 antibody samples enriched from these sera by RBD, S1, S2 and N proteins. Based on these results, we constructed the first map of SARS-CoV-2 specific IgG binding epitopes at single amino acid resolution.

In this study, by applying AbMap, we developed a two-step strategy for profiling pathogen specific epitopes at single amino acid resolution from sera. IgG response is a central part of B cell immunity. Serum or plasma are rich of IgGs for numerous targets that the immune system has encountered, especially when our body is infected by pathogens (22). There is great interest to profile pathogen specific IgG responses by using serum or plasma because of the convenience of sample collection. Protein microarray could be applied to reveal the pathogen specific $\operatorname{IgG}$ responses at protein level $(16,33)$, 
while peptide microarray $(15)$ or pathogen specific peptide library $(19,22)$ were able to provide information at peptide/epitope level. However, these platforms could not provide epitope information at amino acid level, and pathogen specific protein or peptide library need to be constructed individually, which is costly and time-consuming. Alternatively, random peptide libraries were attempted for dissecting pathogen specific $\operatorname{IgG}$ responses from sera $(34,35)$. For SARS-CoV-2, following the protocol of testing serum directly that we established (34), and the K-TOPE algorithm (35), we tried to profile the virus specific IgG responses at proteome level. However, most of the identified epitopes that match the sequence of SARS-CoV-2 proteins are of low frequency. This indicates a more powerful algorithm is needed to dig meaningful epitopes for the random peptide-based strategy. We then simplified the data analysis part by combining MEME and FIMO (36, 37), and identified a set of epitopes of marginly statistical significance (Fig. 1). To experimentally improve the performance of AbMap, we tried to reduce the noise by enriching SARS-CoV-2 specific IgGs using specific proteins or peptides, a larger number of high confident epitopes were identified as compared to that of testing serum directly. Our results clearly point out the directions to improve phage displayed random peptide library-based strategies, such as AbMap, for pathogen specific epitope mapping: 1. Enrich IgGs by protein/ peptide of interest, and 2. Develop algorithm of better performance.

The epitopes that we identified in this study are highly consistent with studies from our group and others. As expected, $\mathrm{S}$ protein and $\mathrm{N}$ protein are among the top list according to $\mathrm{IgG}$ responses (16). High reactivities were also observed for other proteins, for example, NSP3 and NSP12. The different reactivities among the SARS-CoV-2 proteins are correlated to the protein size, but only partially. For example, after normalized by protein size, the highest reactivity was observed for NSP9 (Fig. 2C). It is expected that there are other parameter that cause the difference of IgG reactivity, such as protein level $(30,31)$, further study is needed to investigate this.

At peptide/epitope level, our results are also consistent to other studies. Though using a totally different strategy, we found RBD is lack of, while CTD is rich of linear epitope, the other "hot area" of linear epitope is around the S2' protease cutting site and the fusion peptide. These results are highly consistent to that of the $\mathrm{S}$ protein peptide microarray 
that we constructed (15). According to a SARS-CoV-2 specific peptide library based study (19), the highly immunogenic regions of Spike protein were also enriched in CTD, region around S2' and the fusion peptide, and HR2, which are highly consistent to our study. While aa362-399 of $\mathrm{N}$ protein which identified as high immunogenic region was also determined in our study, but other highly immunogenic regions were not. The inconsistence may be due to the different sample size and the differences of the detailed protocol. According to a peptide microarray (17), 3 of the 6 Spike protein epitopes identified by microarray for serum IgG were also determined as significant epitopes in our study, and aa366-400 of $\mathrm{N}$ protein which identified as a long epitope for serum $\operatorname{IgG}$ was also enriched in our study. Compared to these epitope related studies, our study can serve as an independent cross validation because of the high consistence. Furthermore, this study is the first of such that providing global IgG epitope information at single amino acid level.

There are a variety of possible applications for the significant epitopes/ critical residues identified in this study. According to $\mathrm{S}$ protein, most of the significant epitopes (Fig. S3A) are on the surface of the $3 \mathrm{D}$ structure, it is reasonable to argue that the significant epitopes (including that from $\mathrm{S}$ protein) are naturally of high immunogenicity. Thus, for a given application, one can select one or a few epitopes to generate site specific antibody on demand for $\mathrm{S}$ protein as well as other proteins. High frequencies were observed for some of the epitopes, e. g., Epitope-S1-8 (KFKPFQQF), it is possible this epitope could be used alone or in combination with other epitope for diagnostics. It is known that areas other than RBD on $\mathrm{S}$ protein $(13,38)$, and furthermore, other than RBM on RBD (receptor binding motif) $(8,39)$ may also elicit potent neutralization antibodies. Once determined, the corresponding epitopes could be used directly as vaccine or as immunogen for generating site-specific neutralization antibody. Since the COVID-19 pandemic is unfolding and the sequenced genomes of SARS-CoV-2 is piling up (https://bigd.big.ac.cn/ncov/), undoubtedly, more functionally important amino acid sites will be identified, we can match those sites to the identified critical epitope residues, thus link mutation or SARS-CoV-2 evolution with immune responses. Except for the applications that we discuss here, it is anticipated that more applications of the identified significant epitopes/ critical epitope residues could be explored. 
Taken together, we constructed the first map of SARS-CoV-2 specific IgG binding epitopes at single amino acid resolution. We identified several critical epitope residues on $\mathrm{S}$ protein that are highly correlate to the infectivity of SARS-CoV-2, and the binding of ACE2/ neutralization antibodies to Spike protein. These results facilitate the in-depth understanding of SARS-CoV-2 specific IgG responses, provide direct hints for precise development of diagnostic reagents, therapeutic antibodies and even vaccines.

\section{ACKNOWLEDGEMENTS}

This work was partially supported by National Key Research and Development Program of China Grant (No. 2016YFA0500600), National Natural Science Foundation of China (No. 31970130, 31670831, 31370813 and 31501054), Open Foundation of Key Laboratory of Systems Biomedicine (No. KLSB2020QN-05).

\section{AUTHOR CONTRIBUTIONS}

S.-c. T., X.-d. Z., and H. L. conceived the idea and designed the study; H. Q. performed the epitope mapping of sera and the protein enriched antibodies; M.-1. M. performed the experiments related peptide microarray; H.-w. J., L.-y. C., and H.-n. Z. isolated the SARS-CoV-2 specific antibodies from sera; Z.-w. G., C.-s. H., X.-d. Z., and H. L. performed NGS and the data analysis; J.-y. L., L.-y. C, S.-q. L, X. Y, W. W., J. Z. provided key reagents. All the authors analyzed the data; S.-c. T, H. Q., and M.-1. M. wrote the manuscript. All the authors have read and approved the final manuscript.

\section{DECLARATION OF INTEREST}

The authors declare no conflict of interest.

\section{Data and Code Availability}


All data supporting the findings of this study could be found within the paper and its Supplementary information, and are available from the related databases. The raw data of NGS were deposited in the NCBI SRA Archive (https://www.ncbi.nlm.nih.gov/sra) with BioProject accession number: PRJNA660911. The raw data of peptide microarray were deposited in the Protein Microarray Database (PMD) (http://www.proteinmicroarray.cn/) with experiment accession number: PMDE246.

\section{MATERIALS AND METHODS}

\section{Serum collection}

This study was approved by the Institutional Ethics Review Committee of Foshan Fourth Hospital, Foshan, China. The written informed consent was obtained from each patient. COVID-19 patients were hospitalized and received routine treatment in Foshan Forth hospital during the period from 2020-1-25 to 2020-3-8 with variable stay time (Table S1). When the patients met the standard criteria of hospital discharge, the serum were collected, processed, and stored by standard protocol. As for the hospital discharge criteria, the vital points were normal body temperature, improved respiratory symptoms, lack of inflammation in the pulmonary imaging, and twice consecutively negative for nuclei acid testing. Sera of the control group from Lung cancer patients and healthy controls were collected from Ruijin Hospital, Shanghai, China. All sera were stored at $-80 \square{ }^{\circ} \mathrm{C}$ until use.

\section{Antibody purification}

$\mathrm{S} 2$ and $\mathrm{N}$ were biotinylated according to the manufacturer's protocol. All the biotinylated proteins were incubated with Dynabeads ${ }^{\mathrm{TM}}$ Myone $^{\mathrm{TM}}$ streptavidin $\mathrm{T} 1$ at room temperature for $1 \mathrm{hr}$, the excess proteins were removed by washing the magnetic beads with PBST (PBS containing $0.1 \%$ tween 20). The four biotinylated proteins, $i$. e., RBD, $\mathrm{S} 1, \mathrm{~S} 2$ and $\mathrm{N}$, were immobilized on the surface of magnetic beads, and labelled as RBD::magnetic beads, S1::magnetic beads, S2::magnetic beads and N::magnetic beads, respectively. To deactivate the potential live viruses in the sample, the serum from COVID-19 patients were incubated at $56 \square$ for $1 \mathrm{hr}$. As shown in Fig. S1, these sera were 
incubated with Dynabeads ${ }^{\mathrm{TM}}$ Myone $^{\mathrm{TM}}$ streptavidin T1 to remove the antibodies that bind the free magnetic beads. The sera were incubated consecutively by the RBD::magnetic beads, S1::magnetic beads, S2::magnetic beads and $\mathrm{N}:$ :magnetic beads at $4 \square$, each for 4 hrs. All the magnetic beads, containing the antibodies for each protein, were washed with PBST to remove the non-specific bindings. The antibodies on the beads were eluted with $50 \mathrm{mM}$ glycine $(\mathrm{pH} 2.8)$, and neutralized with Tris buffer (pH8.0). The quality and concentration of the protein enriched antibodies were checked and measured by SDS-PAGE. All the enriched antibodies were stored in $-80 \square$ until in use. The same procedure was followed when enrich antibodies by biotinylated peptides.

\section{Identification of the binding motifs by AbMap}

We followed the AbMap procedure as described previously (20) with slight modifications. Briefly, the 96-well PCR plates were blocked with PBST containing 3\% BSA at $4 \square$ for $16 \mathrm{hrs}$. After washed with PBST, the plates were fulfilled with $200 \mu \mathrm{L}$ PBST. Each well of the plates was loaded with $10 \mu \mathrm{L}$ Ph.D.-12 phage display libraries. The samples, i.e., $1 \mu \mathrm{L}$ for serum sample or a-His antibody and $400 \mathrm{ng}$ for proteins enriched antibodies, were added per well. Blank control was set without the addition of sample, but Ph.D.-12 phage display library. The mixtures were incubated at $4 \square$ for 16 hrs. Dynabesads $^{\mathrm{TM}}$ Protein $\mathrm{G}$ was added into each well to capture the antibody and phage complex. After incubated for $4 \mathrm{hrs}$ at $4 \square$, the magnetic beads in each well were collected and washed. The beads in each well were suspended to $15 \mu \mathrm{L}$ ultrapure water. After boiled at $98 \square$ for $10 \mathrm{~min}$, the supernatant was collected.

To introduce the adapter sequence and unique barcode or index for each sample, two rounds of PCR were carried out on the phage lysate by Q5 hot start polymerase. The first round of PCR was performed by using primers XX-S5XX-23R and XX-N7XX-18 (5'-TCGTCGGCAGCGTCAGATGTGTATAAGAGACAGXXXXXXXXG $\underline{\text { TTGTACC }}$ TTTCTATTCTCACTCT-3',

5'-GTCTCGTGGGCTCGGAGATGTGTATAAGAGA

CAGXXXXXXXXTTCAACAGTTTCGGCCGAACCT-3', where "XXXXXXXX" denotes a 8-nt barcode sequences, and the sequence with the underline was the specific 
primer for amplifying the corresponding nucleotide acid of the displayed peptide from the genome of phage, and the remaining sequence was the Illumina index). After checked by electrophoresis, all the PCR products were mixed. The PCR products were purified and used as the template for the second round PCR. In the second round PCR, the unique indexes of Illumina next generation sequencing (NGS) were introduced for each mixture. After purified by gel extraction, the final sample was ready for NGS.

According to the index and barcode combination, the results of NGS were split and assigned to each sample. For each sample, the data of NGS were trimmed further, and only sequence of $36 \mathrm{bp}$ was left, which corresponded to the 12-mer displayed peptide. All the sequences were translated into peptides, and the frequency of each peptide was counted. If stop codon appeared in the translation process, the corresponding sequence was removed. The enrichment factor of each peptide from the sample were calculated. The reverse enrichment factor of each peptide was also calculated, of which the maximum value was set as the cutoff of the corresponding sample. The peptides, with the enrichment factors lager than the cutoff was determined as the hits. These hits were subjected for MEME analysis, significant motifs were called by setting E value less than 0.05 as the cutoff (40). The significant motifs were matched to SARS-CoV-2 protein/s by FIMO used default settings (36).

\section{Map the epitopes to the 3D structures of the proteins}

A Spike protein structure (PDB ID: 6X6P) was used to analyze the location of the epitopes on the 3D structure. RBD/ACE2 complex structure (PDB ID: 6MOJ), RBD/CR3022 complex (PDB ID: 6W41), RBD/S309 complex (PDB ID: 6WPT), RBD/P2B-2F6 complex (PDB ID: 7BWJ), RBD/BD23 complex (PDB ID: 7BYR) and RBD/CB6 complex (PDB ID: 7C01) were used to analyze the location of the epitopes on these protein complexes. All the structural analyses were processed by using Pymol.

\section{Validation by peptide microarray}

Peptides were synthesized and conjugated to BSA by GL Biochem Ltd. (Shanghai, China). The concentration of each peptide was diluted to $0.5 \mathrm{mg} / \mathrm{mL}, 0.25 \mathrm{mg} / \mathrm{mL}$ and 
$0.125 \mathrm{mg} / \mathrm{mL}$ with PBS containing $40 \%$ glycerin, respectively. According to the pattern showed in Fig. S6, all the peptides, with extra controls, such as the blank control, human IgG, human IgM and land marker Cy5-labelled donkey anti-human IgM, were printed on the surface of PATH slide with 2 x 7 identical subarrays by using Super Marathon printer (Arrayjet, UK). The peptide microarray was stored in $-80^{\circ} \mathrm{C}$ until use.

The assay on the peptide microarray was similar to our previous study (15). Briefly, the peptide microarrays were blocked with PBS containing 3\% BSA. The slides were washed with PBST, and assembled with a 14-chamber rubber gasket. Serum and the enriched antibodies were diluted by 1:200 in incubation buffer and incubated with the array for 2 hrs at room temperature. After three washes with PBST buffer, the arrays were incubated by $\mathrm{Cy3}$-conjugated goat anti-human IgG and Cy5-conjugated donkey anti-human IgM for $1 \mathrm{~h}$ at room temperature at 1: 1000 dilution in 1x PBST. The microarrays were washed three times with $1 \times \mathrm{PBST}$, dried by centrifugation and scanned by LuxScan $10 \mathrm{~K}-\mathrm{A}$ (CapitalBio Corporation, Beijing, China). The fluorescent intensity was extracted by GenePix Pro 6.0 software (Molecular Devices, CA, USA).

\section{Statistical Analysis}

The fluorescent intensity was extracted by GenePix Pro 6.0 software (Molecular Devices, CA, USA). The signal intensity was defined as the mean of the foreground of each spot, and then averaged the three spots of each peptide. All the Signal intensities were analyzed by the software GraphPad Prism version 7.0. 


\section{References}

1. F. Wu et al., A new coronavirus associated with human respiratory disease in China. Nature 579, 265-269 (2020).

2. P. Zhou et al., A pneumonia outbreak associated with a new coronavirus of probable bat origin. Nature 579, 270-273 (2020).

3. E. Dong, H. Du, L. Gardner, An interactive web-based dashboard to track COVID-19 in real time. Lancet Infect Dis 20, 533-534 (2020).

4. K. G. Andersen, A. Rambaut, W. I. Lipkin, E. C. Holmes, R. F. Garry, The proximal origin of SARS-CoV-2. Nat Med 26, 450-452 (2020).

5. Y. Watanabe, J. D. Allen, D. Wrapp, J. S. McLellan, M. Crispin, Site-specific glycan analysis of the SARS-CoV-2 spike. 369, 330-333 (2020).

6. Y. $\mathrm{Wu}$ et al., A noncompeting pair of human neutralizing antibodies block COVID-19 virus binding to its receptor ACE2. Science 368, 1274-1278 (2020).

7. Y. Cao et al., Potent Neutralizing Antibodies against SARS-CoV-2 Identified by High-Throughput Single-Cell Sequencing of Convalescent Patients' B Cells. Cell 182, 73-84 e16 (2020).

8. M. Yuan et al., A highly conserved cryptic epitope in the receptor binding domains of SARS-CoV-2 and SARS-CoV. Science 368, 630-633 (2020).

9. A. Z. Wec et al., Broad neutralization of SARS-related viruses by human monoclonal antibodies. Science 369, 731-736 (2020).

10. A. Baum et al., Antibody cocktail to SARS-CoV-2 spike protein prevents rapid mutational escape seen with individual antibodies. Science 369, 1014-1018 (2020).

11. T. F. Rogers et al., Isolation of potent SARS-CoV-2 neutralizing antibodies and protection from disease in a small animal model. Science 369, 956-963 (2020).

12. C. M. Poh et al., Two linear epitopes on the SARS-CoV-2 spike protein that elicit neutralising antibodies in COVID-19 patients. Nature Communications 11, 2806 (2020).

13. X. Chi et al., A neutralizing human antibody binds to the N-terminal domain of the Spike protein of SARS-CoV-2. 369, 650-655 (2020).

14. Y. Li et al., Linear epitope landscape of SARS-CoV-2 Spike protein constructed from 1,051 COVID-19 patients. 2020.2007.2013.20152587 (2020).

15. Y. Li et al., Linear epitopes of SARS-CoV-2 spike protein elicit neutralizing antibodies in COVID-19 patients. Cellular \& Molecular Immunology, in press (2020).

16. H. W. Jiang et al., SARS-CoV-2 proteome microarray for global profiling of COVID-19 specific IgG and IgM responses. Nat Commun 11, 3581 (2020).

17. H. Wang et al., SARS-CoV-2 proteome microarray for mapping COVID-19 antibody interactions at amino acid resolution. bioRxiv, 2020.2003.2026.994756 (2020).

18. W. Liu et al., Evaluation of Nucleocapsid and Spike Protein-based ELISAs for detecting antibodies against SARS-CoV-2. Journal of clinical microbiology, (2020).

19. C. R. Zamecnik et al., ReScan, a Multiplex Diagnostic Pipeline, Pans Human Sera for SARS-CoV-2 Antigens. medRxiv, 2020.2005.2011.20092528 (2020). 
20. H. Qi et al., Antibody binding epitope Mapping (AbMap) of two hundred antibodies in a single run. 739342 (2019).

21. R. A. Manz, A. E. Hauser, F. Hiepe, A. Radbruch, MAINTENANCE OF SERUM ANTIBODY LEVELS. 23, 367-386 (2005).

22. G. J. Xu et al., Comprehensive serological profiling of human populations using a synthetic human virome. 348, aaa0698 (2015).

23. N. G. Herrera et al., Characterization of the SARS-CoV-2 S Protein: Biophysical, Biochemical, Structural, and Antigenic Analysis. bioRxiv, 2020.2006.2014.150607 (2020).

24. E. A. Emini, J. V. Hughes, D. S. Perlow, J. Boger, Induction of hepatitis A virus-neutralizing antibody by a virus-specific synthetic peptide. J Virol 55, 836-839 (1985).

25. J. Lan et al., Structure of the SARS-CoV-2 spike receptor-binding domain bound to the ACE2 receptor. Nature 581, 215-220 (2020).

26. D. Pinto et al., Structural and functional analysis of a potent sarbecovirus neutralizing antibody. bioRxiv, (2020).

27. B. Ju et al., Human neutralizing antibodies elicited by SARS-CoV-2 infection. Nature 584, 115-119 (2020).

28. R. Shi et al., A human neutralizing antibody targets the receptor-binding site of SARS-CoV-2. Nature 584, 120-124 (2020).

29. Q. Li et al., The Impact of Mutations in SARS-CoV-2 Spike on Viral Infectivity and Antigenicity. Cell, (2020).

30. D. Kim et al., The Architecture of SARS-CoV-2 Transcriptome. Cell 181, 914-921.e910 (2020).

31. Y. Finkel et al., The coding capacity of SARS-CoV-2. 2020.2005.2007.082909 (2020).

32. N. M. A. Okba et al., Severe Acute Respiratory Syndrome Coronavirus 2-Specific Antibody Responses in Coronavirus Disease 2019 Patients. Emerging infectious diseases 26, (2020).

33. J. Deng et al., Mycobacterium Tuberculosis Proteome Microarray for Global Studies of Protein Function and Immunogenicity. Cell Rep 9, 2317-2329 (2014).

34. F. L. Wu et al., Identification of Serum Biomarkers for Systemic Lupus Erythematosus Using a Library of Phage Displayed Random Peptides and Deep Sequencing. Mol Cell Proteomics 18, 1851-1863 (2019).

35. M. L. Paull, T. Johnston, K. N. Ibsen, J. D. Bozekowski, P. S. Daugherty, A general approach for predicting protein epitopes targeted by antibody repertoires using whole proteomes. PLoS One 14, e0217668 (2019).

36. C. E. Grant, T. L. Bailey, W. S. Noble, FIMO: scanning for occurrences of a given motif. Bioinformatics 27, 1017-1018 (2011).

37. T. L. Bailey, C. Elkan, Fitting a mixture model by expectation maximization to discover motifs in biopolymers. Proc Int Conf Intell Syst Mol Biol 2, 28-36 (1994).

38. Z. Lv et al., Structural basis for neutralization of SARS-CoV-2 and SARS-CoV by a potent therapeutic antibody. Science, (2020).

39. D. Zhou et al., Structural basis for the neutralization of SARS-CoV-2 by an antibody from a convalescent patient. Nat Struct Mol Biol, (2020). 
40. T. L. Bailey et al., MEME SUITE: tools for motif discovery and searching. Nucleic Acids Res 37, W202-208 (2009).

\section{FIGURE LEGENDS}

Figure 1. The schematic diagram of using AbMap to determine SARS-CoV-2 IgG binding epitopes. Three types of samples, i.e. sera, protein specific antibodies enriched from sera, and peptide/ epitope specific antibodies enriched from sera, were subjected for epitope mapping using AbMap technology. Significant epitopes were enriched for all these three layers of samples. The matched sequences on the targeting proteins were shown for protein and peptide enriched antibodies.

\section{Figure 2. The map of SARS-CoV-2 specific IgG binding epitopes revealed from} convalescent sera directly. (A) The epitopes (Table S3) of each patient (P1-P55) were plotted alongside the known SARS-CoV-2 proteins from $\mathrm{N}$ terminal to $\mathrm{C}$ terminal. The total number of the identified epitopes for each patient and each protein were defined as frequency and sum_epitopes, respectively. (B) The histogram of the epitope frequency (bin $=4)$. (C) The sum_epitopes of each protein.

Figure 3. Significant epitopes on $\mathbf{S}$ protein. (A) The distribution of the sequence-matched epitopes on $\mathrm{S}$ protein. (B) The distribution of the significant epitopes (frequency $>=3$ ) on the monomer 3D structure of the $\mathrm{S}$ protein. Red marked amino acids represent key residues of epitopes. (C) A representative significant epitope. (D) The epitope was matched to S protein, critical residues were labeled as yellow. (E) Homology analysis of the epitope among three deadly coronaviruses, i. e., SARS-CoV-2, SARS-CoV and MERS-CoV, four common human coronaviruses, i. e., HCoV-OC43, HKU-1, NL63 and 229E and the highly homologous bat coronavirus BtCoV-RaTG13. 
Figure 4. Functional analysis of several key sites of the significant epitopes of $S$ protein. (A) One relatively significant epitope (frequency $>=2$ ) was identified for RBD enriched antibody. (B) Match the critical epitope residues to the structure of RBD. (C) The critical epitope residues locate adjacent to but not at the binding interfaces of RBD and ACE2. (D and E) The critical epitope residues locate adjacent to but not at the binding interfaces of RBD by two highly potent neutralization antibodies, CR3022-Fab (D) and S309-Fv (E). (F) Match the epitopes on S protein with the critical naturally existing mutants (29).

Figure 5. Significant epitopes on $\mathbf{N}$ protein. (A) The distribution of the sequence-matched epitopes on $\mathrm{N}$ protein. (B) The list of significant epitopes (frequency $>=3$ ). (C) Homology analysis of the significant epitopes among three deadly coronaviruses, i. e., SARS-CoV-2, SARS-CoV and MERS-CoV, four common human coronaviruses, i. e., HCoV-OC43, HKU-1, NL63 and 229E and the highly homologous bat coronavirus BtCoV-RaTG13.

Figure 6. Validation of epitopes by a peptide microarray. (A) Selected samples were subjected for peptide microarray validation. The summary of the validation results. (B) The microarray results of selected samples against three representative epitopes. Sample with red label indicates the corresponding epitope was identified from this sample by AbMap. While other samples were included as negative controls for corresponding epitopes.

\section{SUPPLEMENTAL FIGURE LEGENDS}

Figure S1. Protein specific antibodies enrichment from COVID 19 convalescent sera. COVID-19 convalescent sera were used as input. Terminal biotinylated proteins were 
used as baits to enrich specific antibodies. SA conjugated magnetic beads were adopted to isolate the antibodies.

Figure S2. Protein based antibody enrichment is necessary for AbMap. S protein specific epitopes identified from sera directly (black dot), and S1+S2 protein enriched antibodies (red dot).

Figure S3. Detailed information of the significant epitopes on S protein. (A) The list of the significant epitopes (frequency >=3), (B) The distribution of the significant epitopes (frequency>=3) on the trimer 3D structure of the S protein. Red marked amino acids represent critical residues of epitopes.

Figure S4. Additional structure analysis of a significant epitope on RBD and Naturelly existing mutants of Spike protein. (A-C) The key residues locate adjacent to but not at the binding interfaces of RBD by other three highly potent neutralization antibodies, P2B-2F6-Fab (A), BD23-Fab (B) and CB6-Fab (C). (D) The Substitution mutants of Spike protein collected by China National Center for Bioinformation (CNCB) were plotted alongside the Spike protein with the mutated frequency. (The data were collected by 2020-8-26)

Figure S5. Validation of epitopes by a peptide microarray: the comparison of sera and protein enriched antibodies. Peptide 1 (Pep 1), which corresponds to Epitope-S1-8 (KLFPFQQF) was selected as an example. Sample with red label indicates the corresponding epitope was identified from this sample by AbMap. The ratio of signal_intensity (S1 enriched)/ signal_intensity (serum) for each residue was plotted (right). 
Figure S6. The layout of the peptide microarray of 4 significant epitopes. (A) Quality control of the peptide microarray. All the peptides were chemically synthesized and conjugated to BSA. The BSA conjugated peptides were printed and immobilized on the microarray. The microarray was stained with an anti-BSA antibody and followed with a Cy5 conjugated secondary antibody. (B) The layout of the peptide microarray. (C) The sequences of the peptides that were included on the peptide microarray.

Table S1. Serum samples tested in this study.

Table S2. All the identified motifs.

Table S3. The identified epitopes that match the sequences of SARS-CoV-2 proteins.

Table S4. Structure and homology analysis of significant epitopes. Two significant epitopes. The epitopes were matched to $\mathrm{S}$ protein, critical epitope residues were labeled as yellow. Homology analysis of the epitope among three deadly coronaviruses, four common human coronaviruses, and bat coronavirus BtCoV-RaTG13. 


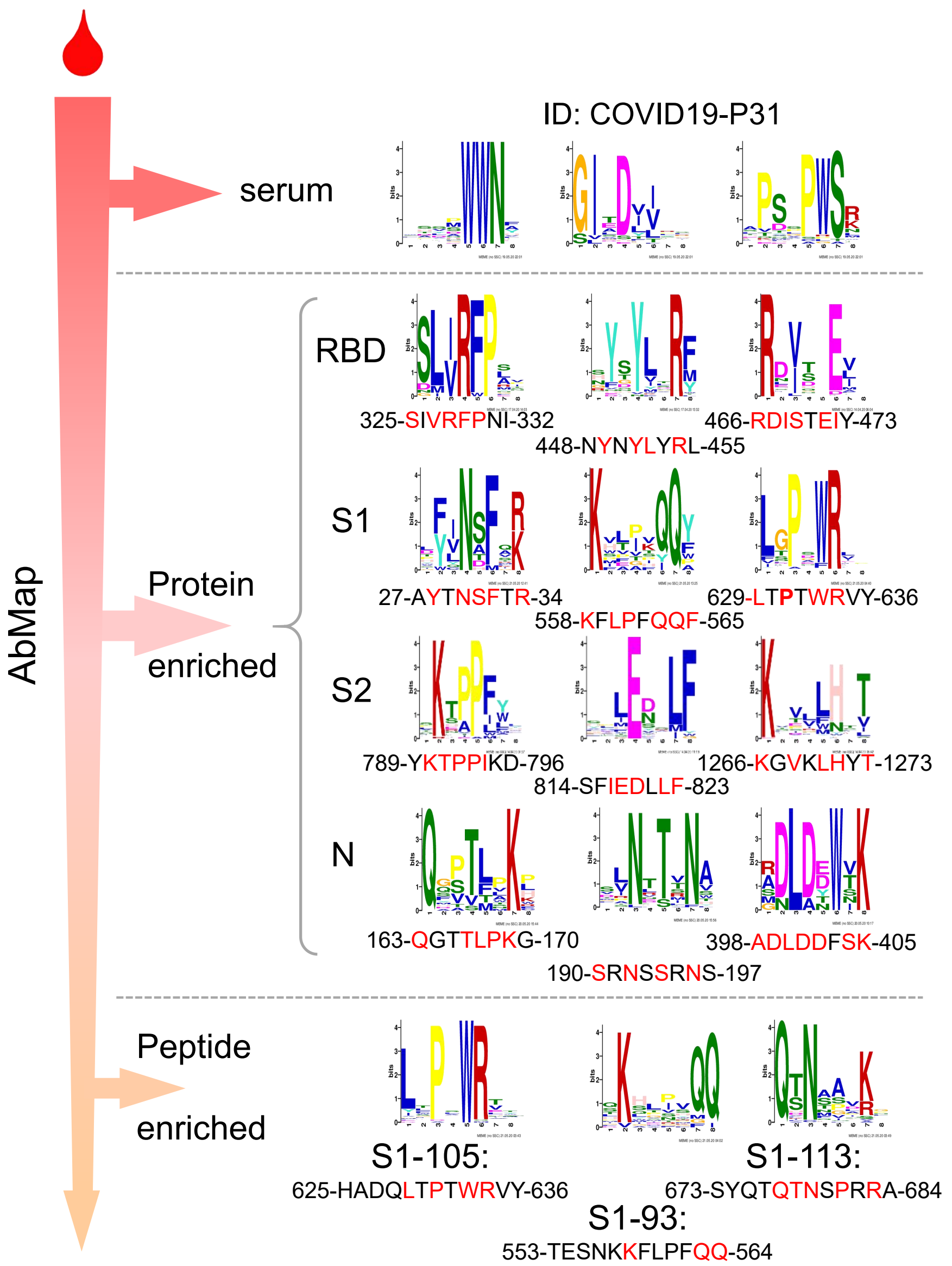

Qi et al., Figure 1 
eer review) Is the author/tunder, who has granted medRXIV a license to
It is made available under a CC-BY-NC-ND 4.0 International license .

A

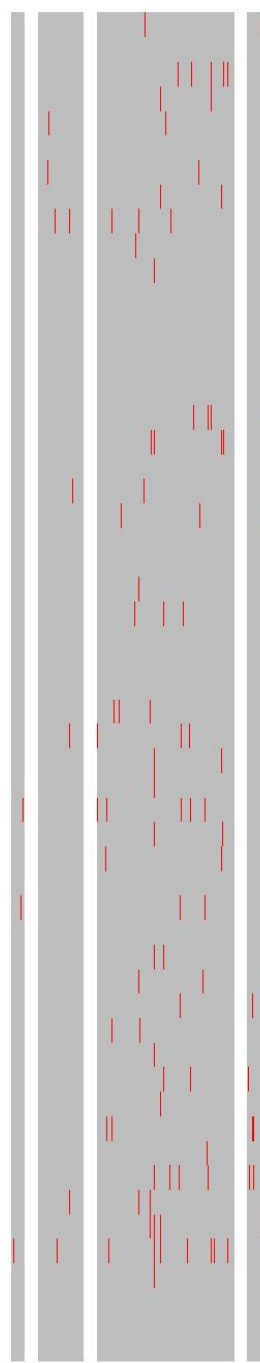

$\overline{0}$ co
- Positive - Negative
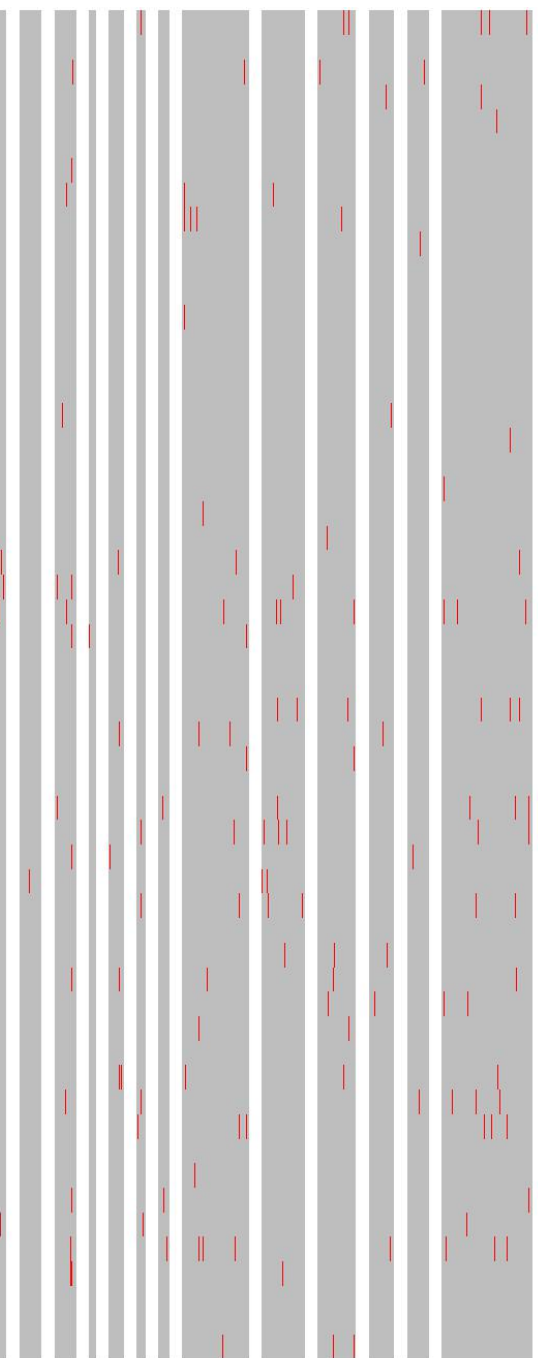

||| || || $\mid$ ||

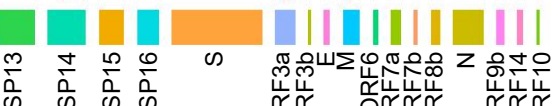

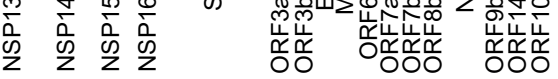

\section{Patient}

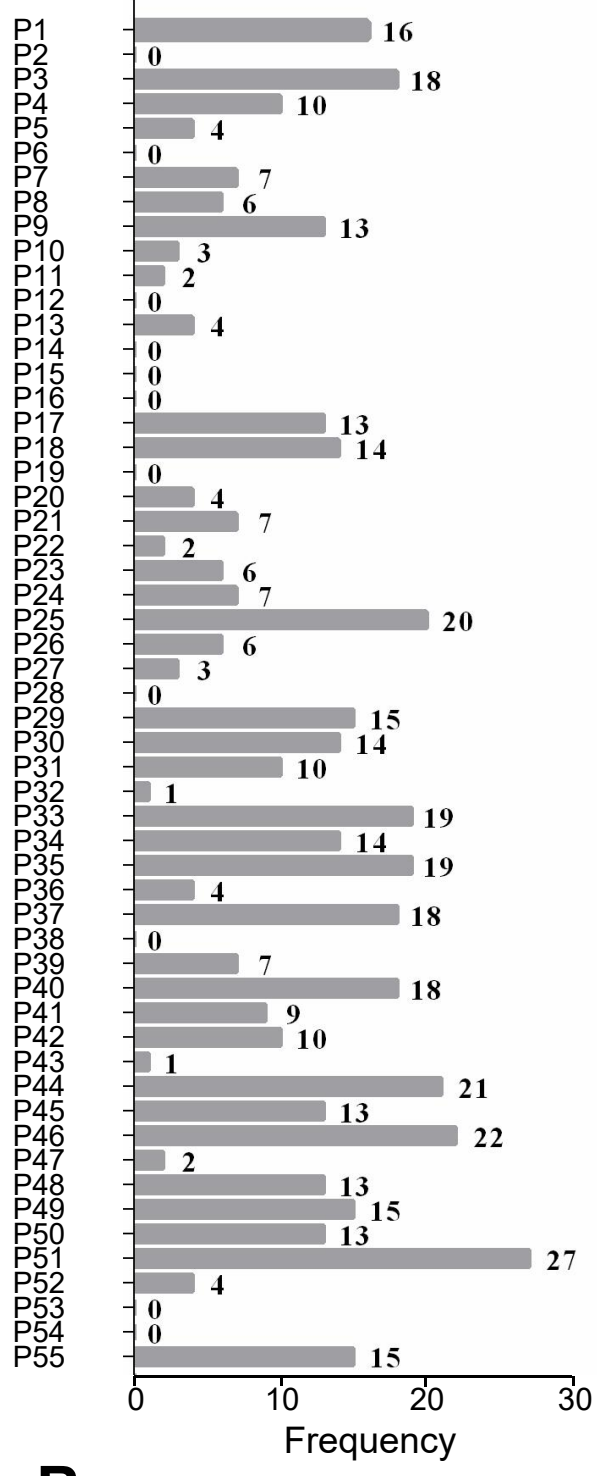

B

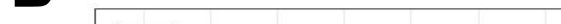

C
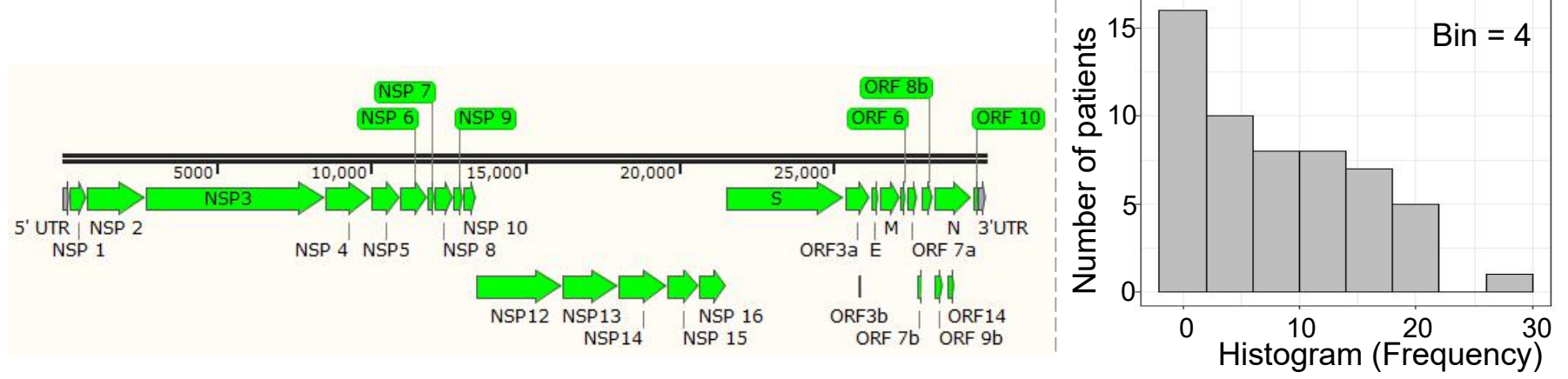

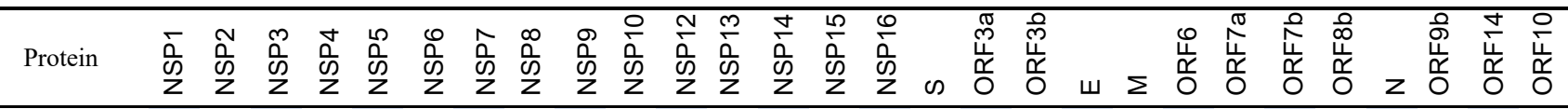

$\begin{array}{lllllllllllllllllllllllllllllllllll}\text { Sum_epitopes } & 8 & 16 & 125 & 30 & 7 & 20 & 1 & 8 & 9 & 3 & 48 & 22 & 26 & 9 & 11 & 69 & 9 & 1 & 1 & 12 & 0 & 3 & 2 & 2 & 20 & 1 & 5 & 1\end{array}$

$\begin{array}{llllllllllllllllllllllllllllll}\text { Length } & 180 & 638 & 1945 & 500 & 306 & 290 & 83 & 198 & 113 & 139 & 932 & 601 & 527 & 346 & 298 & 1273 & 275 & 22 & 75 & 222 & 61 & 121 & 43 & 121 & 419 & 97 & 73 & 38\end{array}$

$\begin{array}{lllllllllllllllllllllllllllllllllll}\text { Sum_epitopes/ } & 0.04 & 0.03 & 0.06 & 0.06 & 0.02 & 0.07 & 0.01 & 0.04 & 0.08 & 0.02 & 0.05 & 0.04 & 0.05 & 0.03 & 0.04 & 0.05 & 0.03 & 0.05 & 0.01 & 0.05 & 0.00 & 0.02 & 0.05 & 0.02 & 0.05 & 0.01 & 0.07 & 0.03\end{array}$

Length
} 


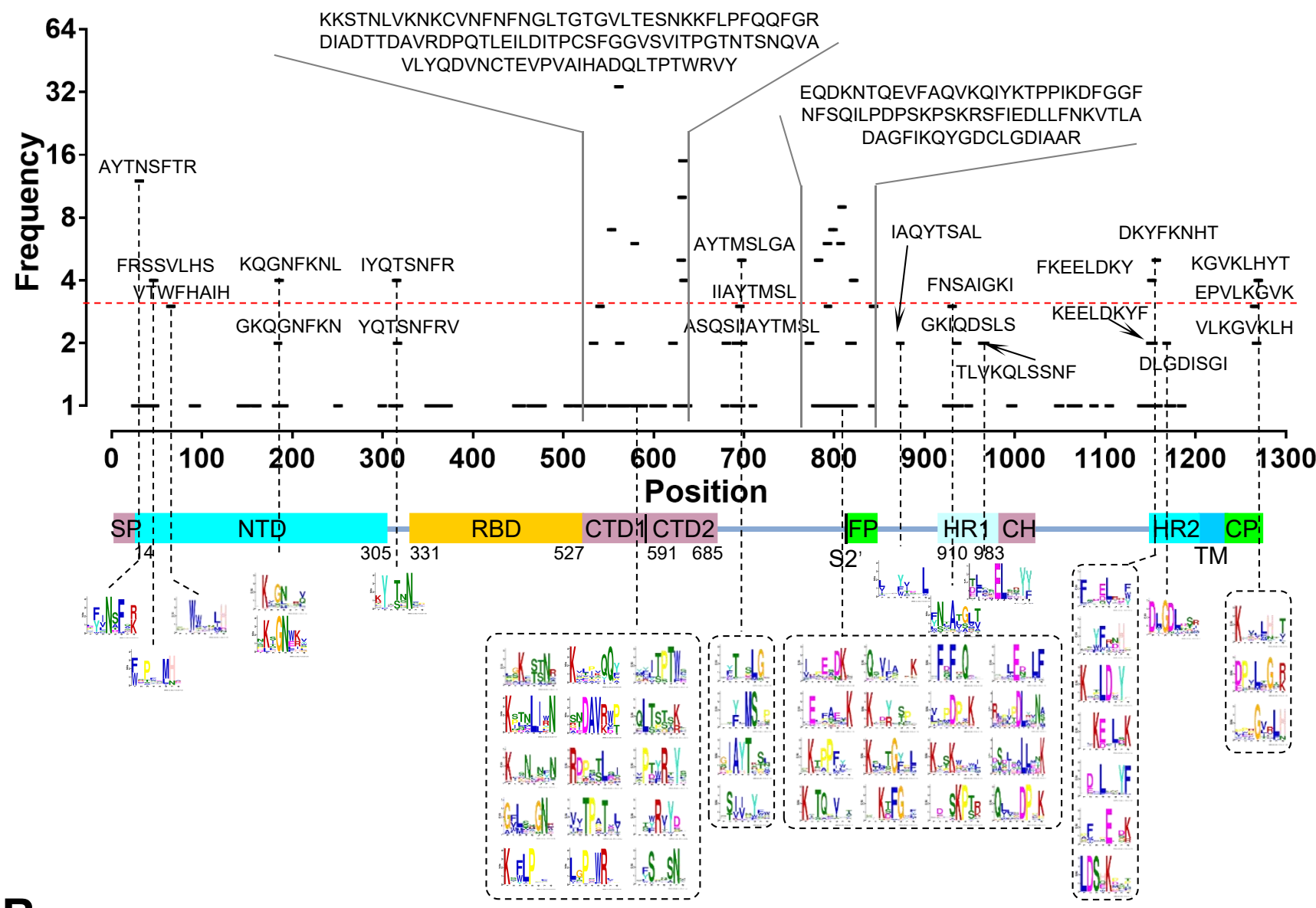

B

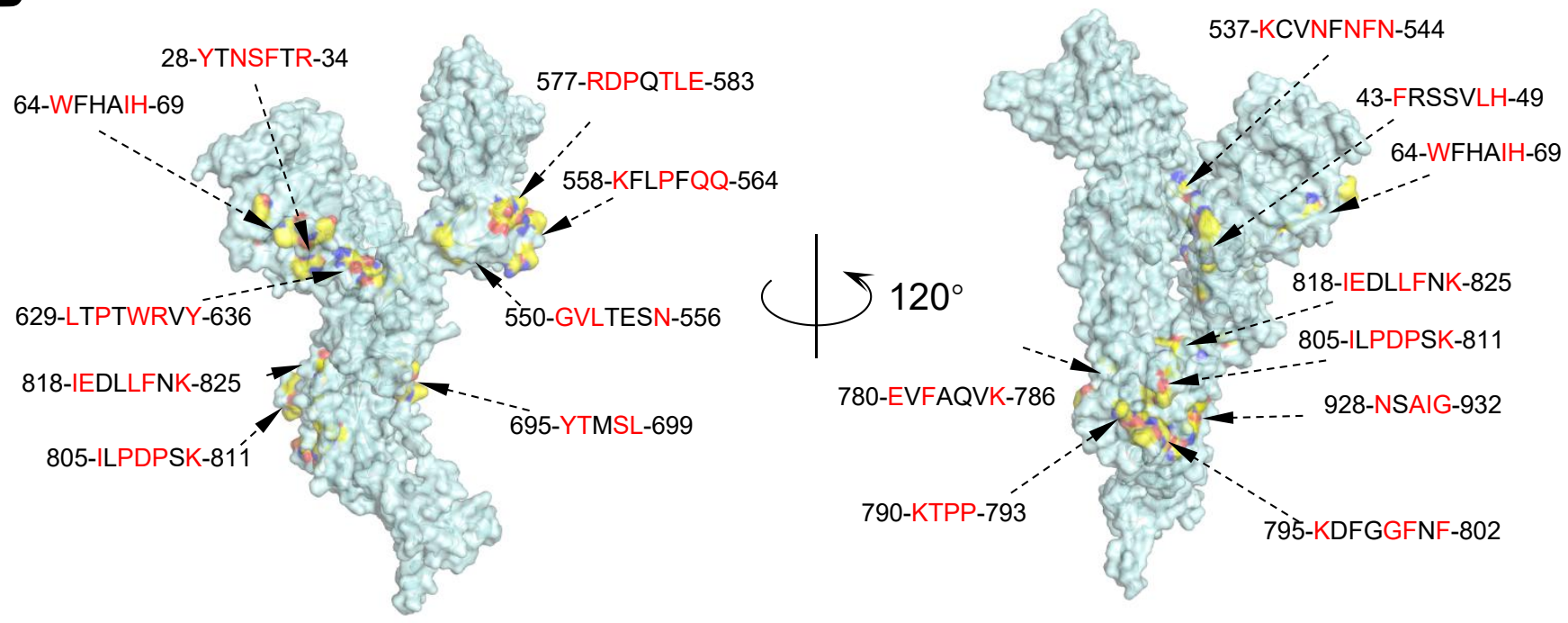

C

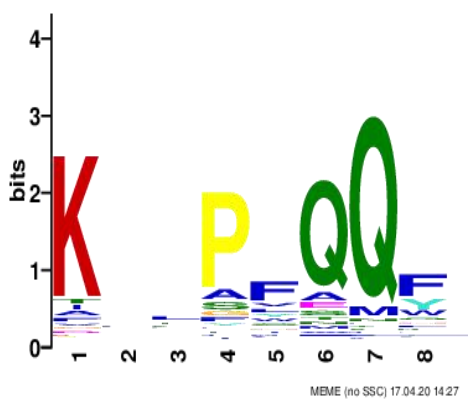

S1\& S2 protein enriched

display the preprint in perpetu KKSTNLVKNKCVNFNFNGLTGTGVLTESNKKFLPFQQFGR

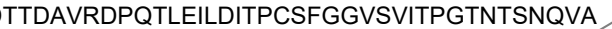
VLYQDVNCTEVPVAIHADQLTPTWRVY 
A

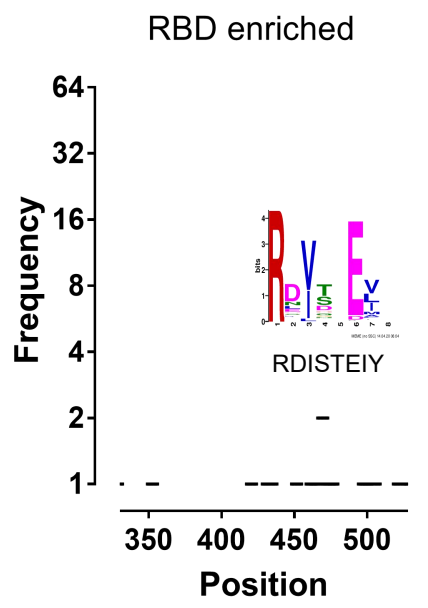

C

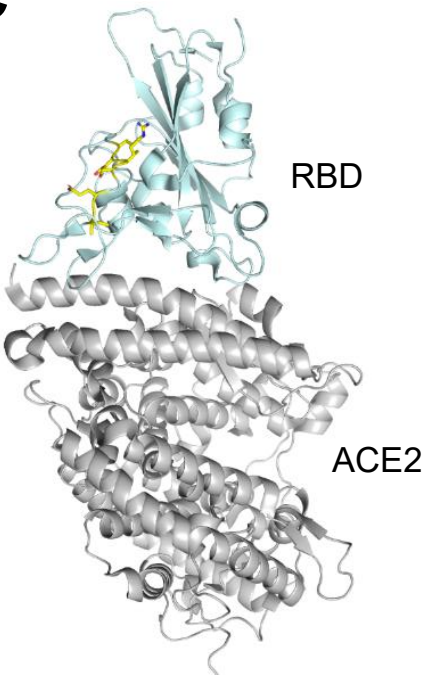

$\mathbf{F}$

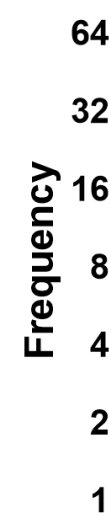

B
D

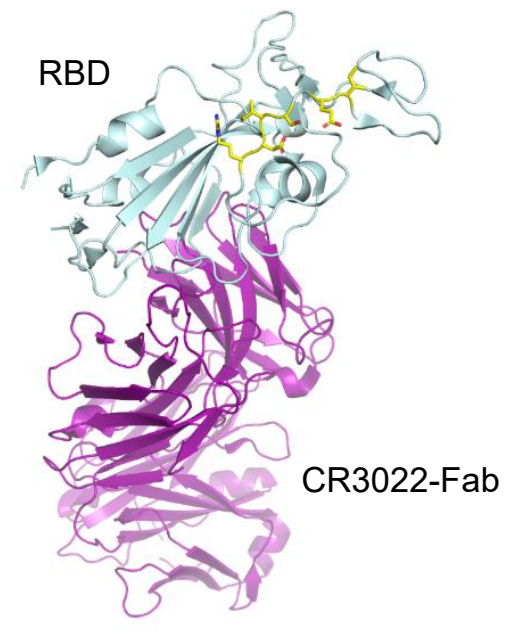

S1 \& S2 protein enriched
E

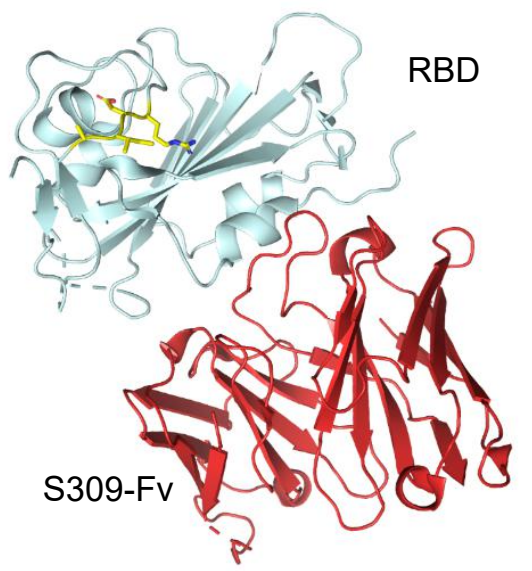

- Motif

- Mutate site

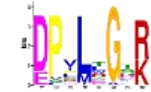<smiles>C[18OH]</smiles>

에.

D936Y

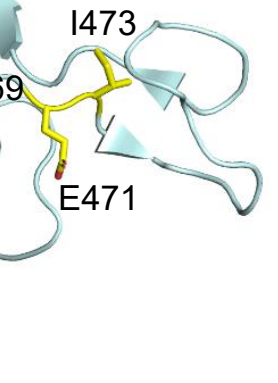

display the preprint in perpetu 
$\mathrm{N}$ protein enriched

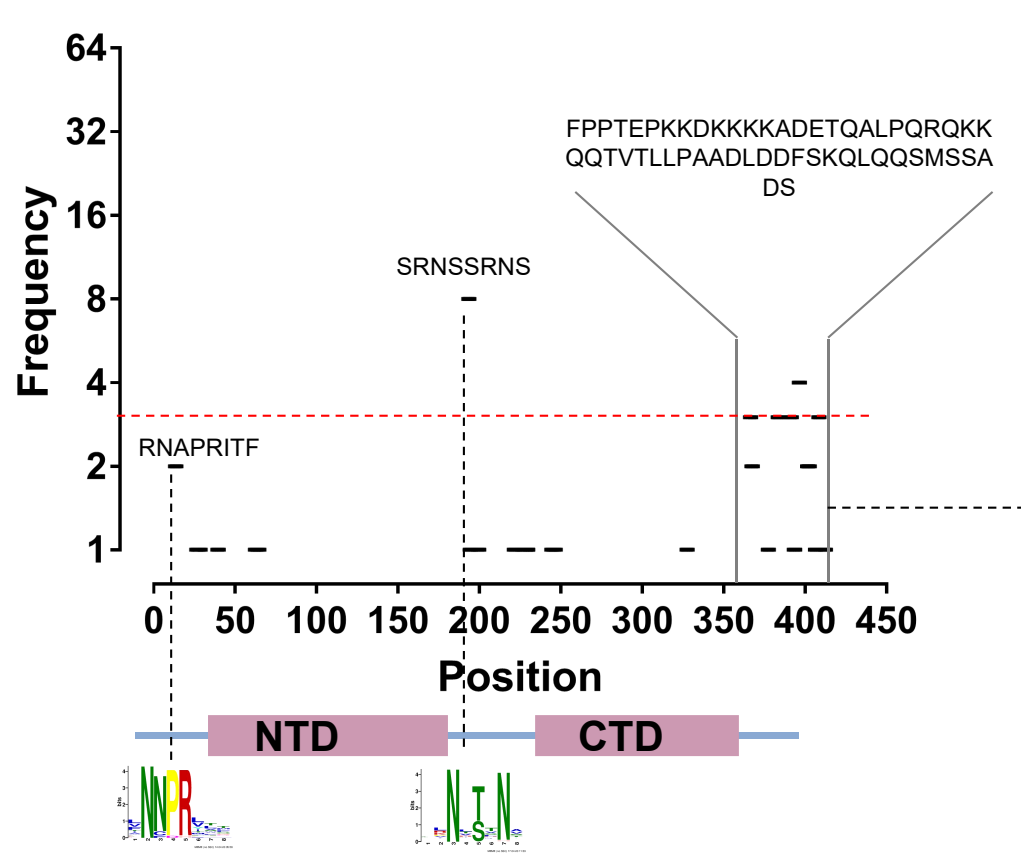

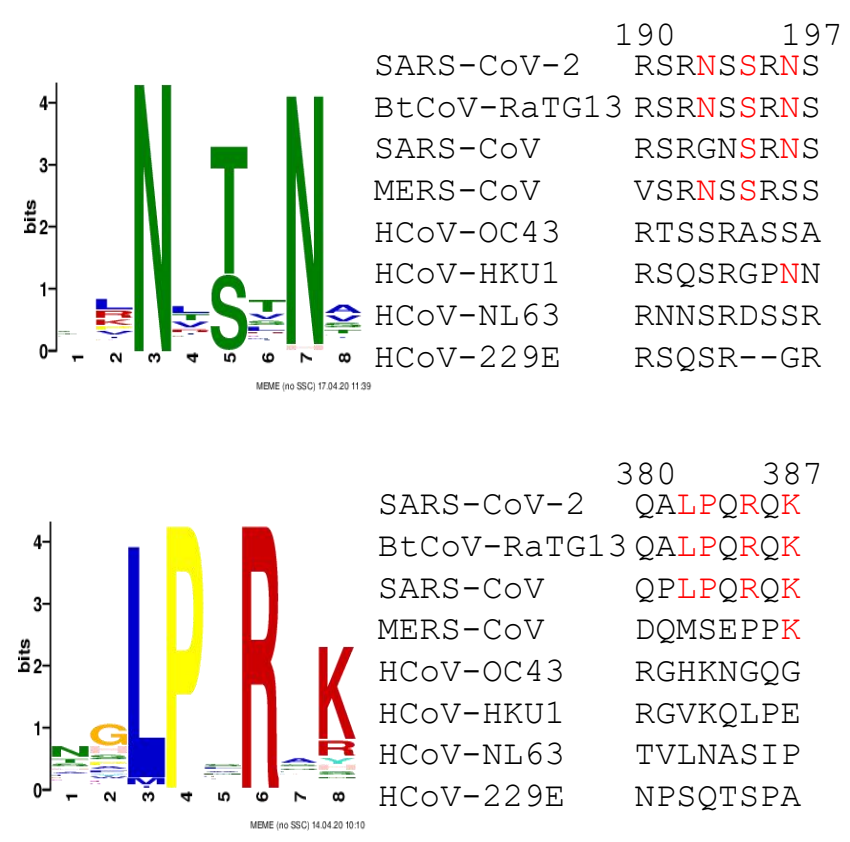

SARS-COV-2 400

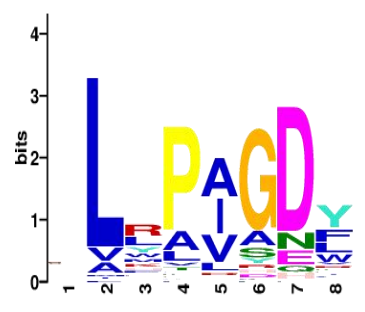

393

SARS-COV-2 RSRNSSRNS

BtCoV-RaTG13 RSRNSSRNS

MERS-COV VSRNSSRSS

HCOV-OC 43 RTSSRASSA

HCOV-HKU1 RSQSRGPNN

RSQSR--GR

$380 \quad 387$

BtCoV-RaTG13 TLLPA---------ADL

SARS-COV

MERS-COV

$\mathrm{HCOV}-\mathrm{OC} 43$

$\mathrm{HCOV}-\mathrm{HKU} 1$

$\mathrm{HCOV}-\mathrm{NL} 63$

$\mathrm{HCOV}-229 \mathrm{E}$
TLLPA--------ADM

GSITQ---------RTR

SVAVPKSRVQQNKSREL

NLSAG----TQHISNDF

ADDDS------------

RDEVS -
HCOV-NL63 RNNSRDSSR

\begin{tabular}{ccccc}
\hline No. & ID & \multicolumn{2}{c}{ Sequence Position Frequency } \\
\hline 1 & Epitope-N-1 & SRNSSRNS & $190-197$ & 8 \\
2 & Epitope-N-2 & FPPTEPKK & $363-370$ & 3 \\
3 & Epitope-N-3 & QALPQRQK & $380-387$ & 3 \\
4 & Epitope-N-4 & KQQTVTLL & $388-395$ & 3 \\
5 & Epitope-N-5 & TLLPAADL & $393-400$ & 4 \\
6 & Epitope-N-6 & KQLQQSMS & $405-412$ & 3 \\
\hline
\end{tabular}

B

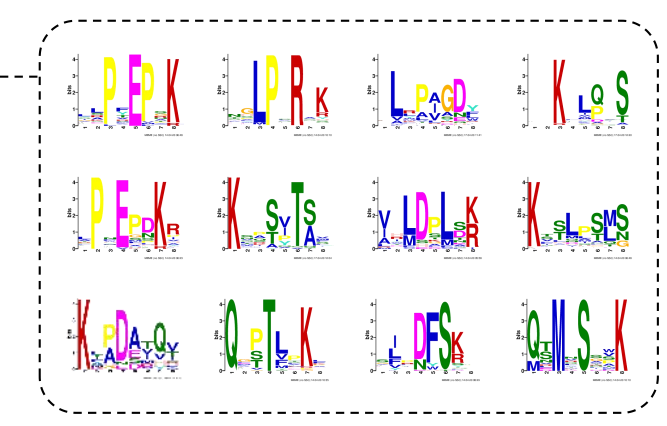

C

SARS-COV-2 $\begin{array}{cr}363 & 370 \\ \text { FPPTEPKK }\end{array}$

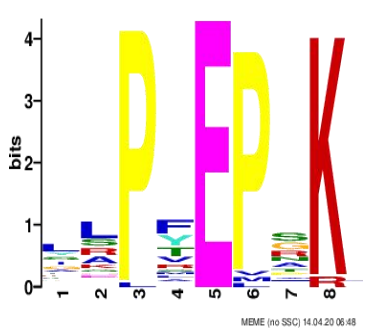

BtCoV-RaTG13 FPPTEPKK

SARS-COV FPPTEPKK

MERS-COV FPKKE-KK

HCOV-OC43 --QQDGMM

HCOV-HKU1 SNQNTDSD

HCOV-NL63 PSSIKEMQ

HCOV-229E --EMQQHP

$388 \quad 395$

SARS-COV-2 KQQTVTLL BtCoV-RaTG13 KQQTVTLL

SARS-COV KQPTVTLL

MERS-COV EQRVQGSI

$\mathrm{HCOV}-\mathrm{OC} 43$ ENDNISVA

HCOV-HKU1 QFDSLNLS

HCOV-NL 63 ESKPLADD

HCOV-229E TAEPVRDE

$405 \quad 412$

SARS-COV-2 KQLQQSMS

BtCoV-RaTG13 KQLQQSMS

SARS-COV RQLQNSMS

MERS-COV VQPGPMID

$\mathrm{HCOV}-\mathrm{OC} 43$ ISLLKKMD

HCOV-HKU1 HSLLATLD

HCOV-NL 63 IEIVNEVL

HCOV-229E TDIIDEVN 
A It is made available under a CC-BY-NC-ND 4.0 International license.

\begin{tabular}{ccccccc}
\hline \multirow{2}{*}{ Patient No. } & \multicolumn{2}{c}{ epitope-KFLPFQQF } & \multicolumn{2}{c}{ epitope-LTPTWRVY } & \multicolumn{2}{c}{ epitope-RDISTEIY } \\
& AbMap & Microarray & AbMap & Microarray & AbMap & Microarray \\
\hline P1 & $\sqrt{ }$ & $\sqrt{ }$ & N.D. & $\sqrt{ }$ & N.D. & $\sqrt{ }$ \\
P42 & $\sqrt{ }$ & $\sqrt{ }$ & $\sqrt{ }$ & N.D. & $\sqrt{ }$ & $\sqrt{ }$ \\
P44 & $\sqrt{ }$ & $\sqrt{ }$ & $\sqrt{ }$ & $\sqrt{ }$ & N.D. & $\sqrt{ }$ \\
P45 & $\sqrt{ }$ & $\sqrt{ }$ & $\sqrt{ }$ & $\sqrt{ }$ & N.D. & $\sqrt{ }$ \\
P28 & $\sqrt{ }$ & $\sqrt{ }$ & $\sqrt{ }$ & $\sqrt{ }$ & N.D. & $\sqrt{ }$ \\
\hline
\end{tabular}

\section{B}

P44
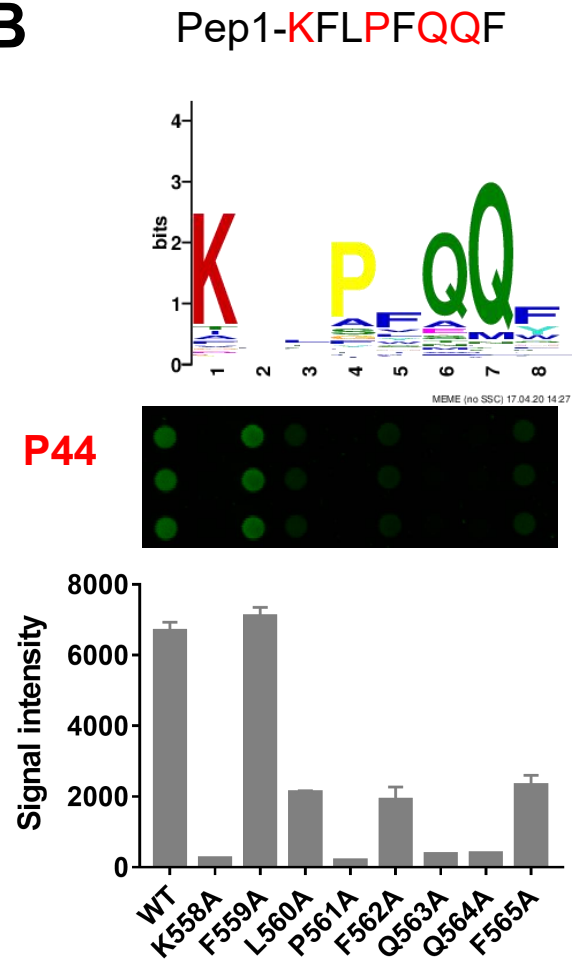

P45
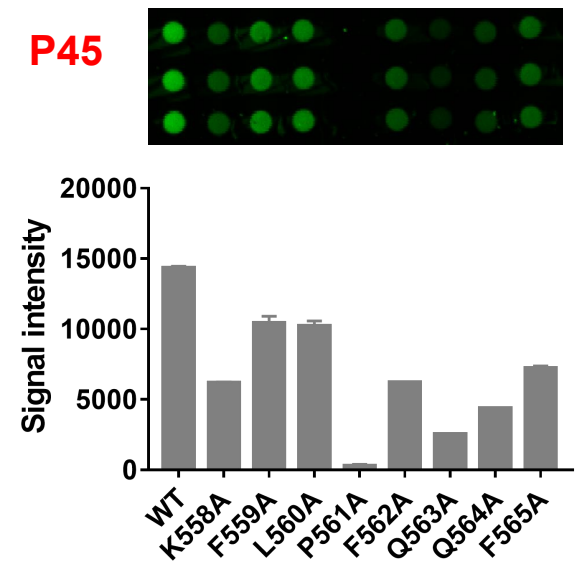

P28

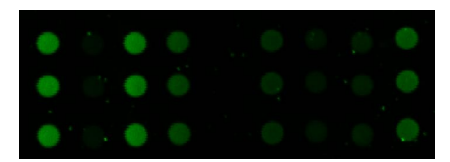

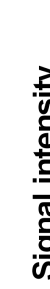

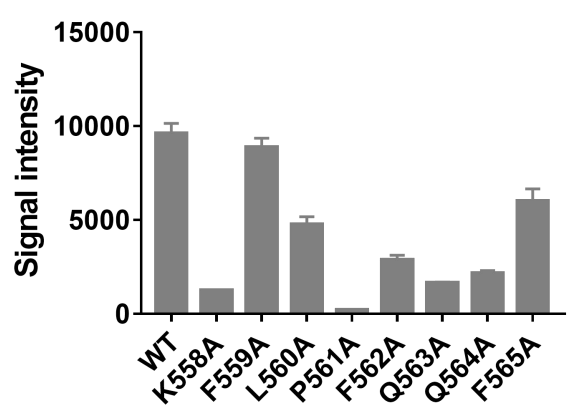

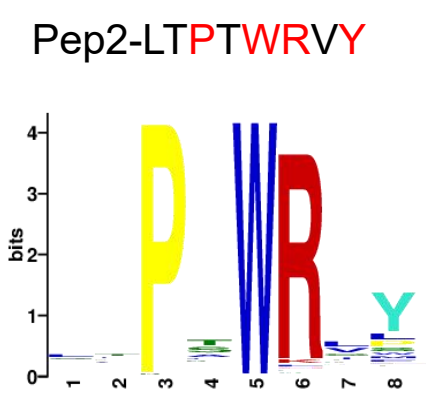

\section{P44}
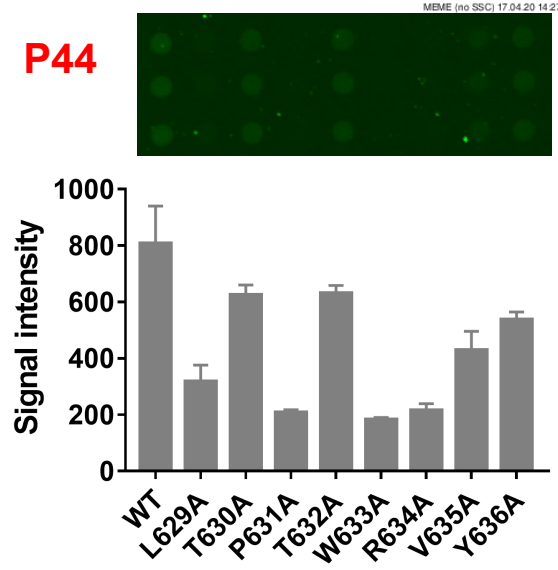

\section{P45}
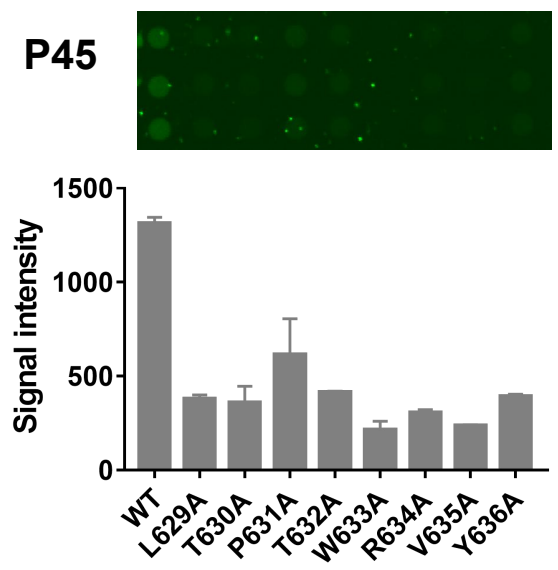

P28
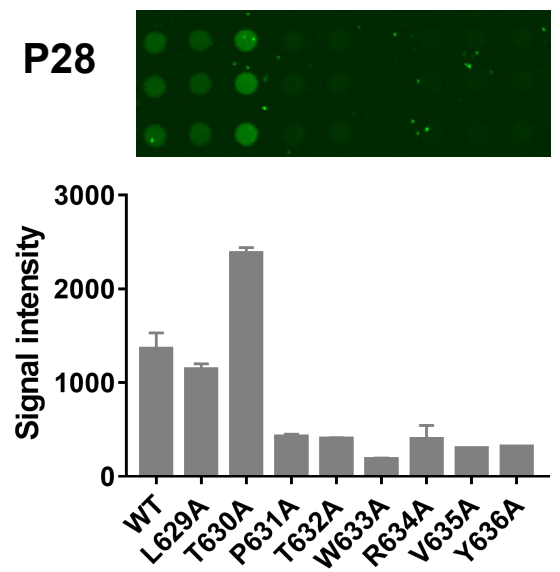

Pep4-RDISTEIY

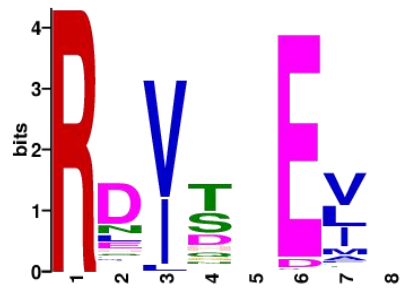

P42
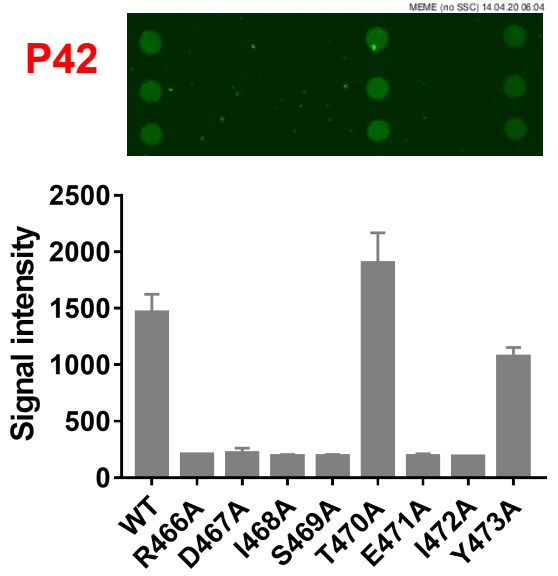

P1
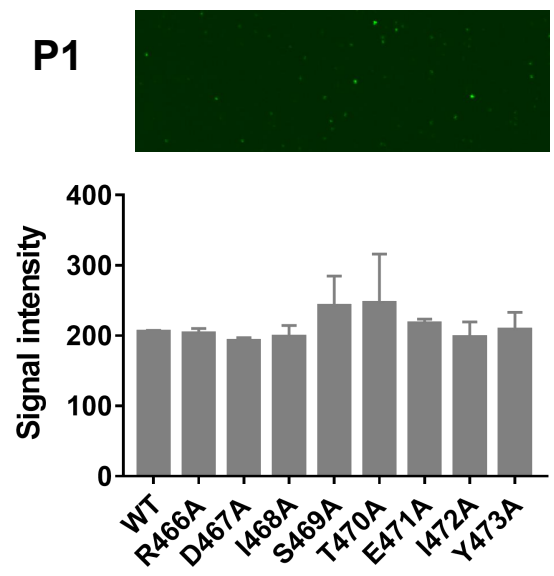

P44

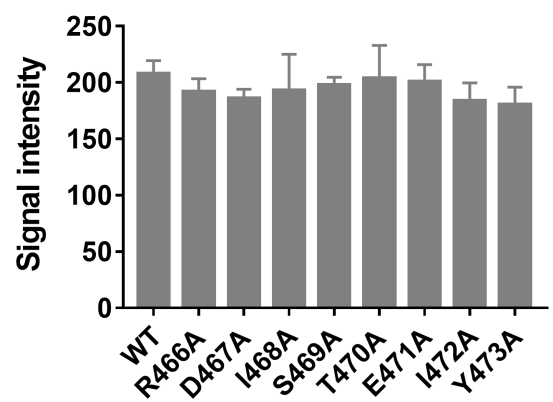

Qi et al., Figure 6 


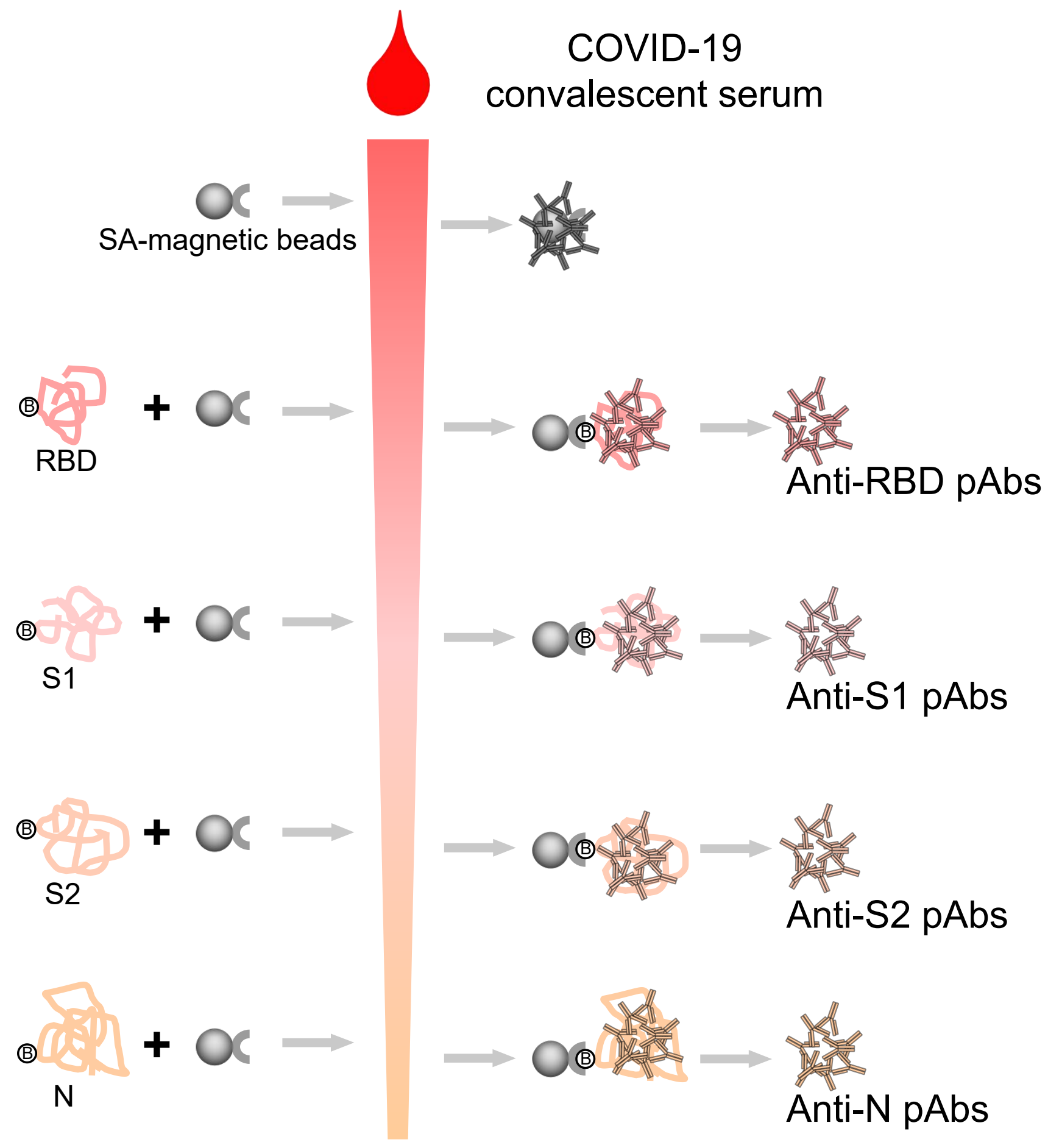

Qi et al., Figure S1 
Serum vs. S1 \& S2 protein enriched

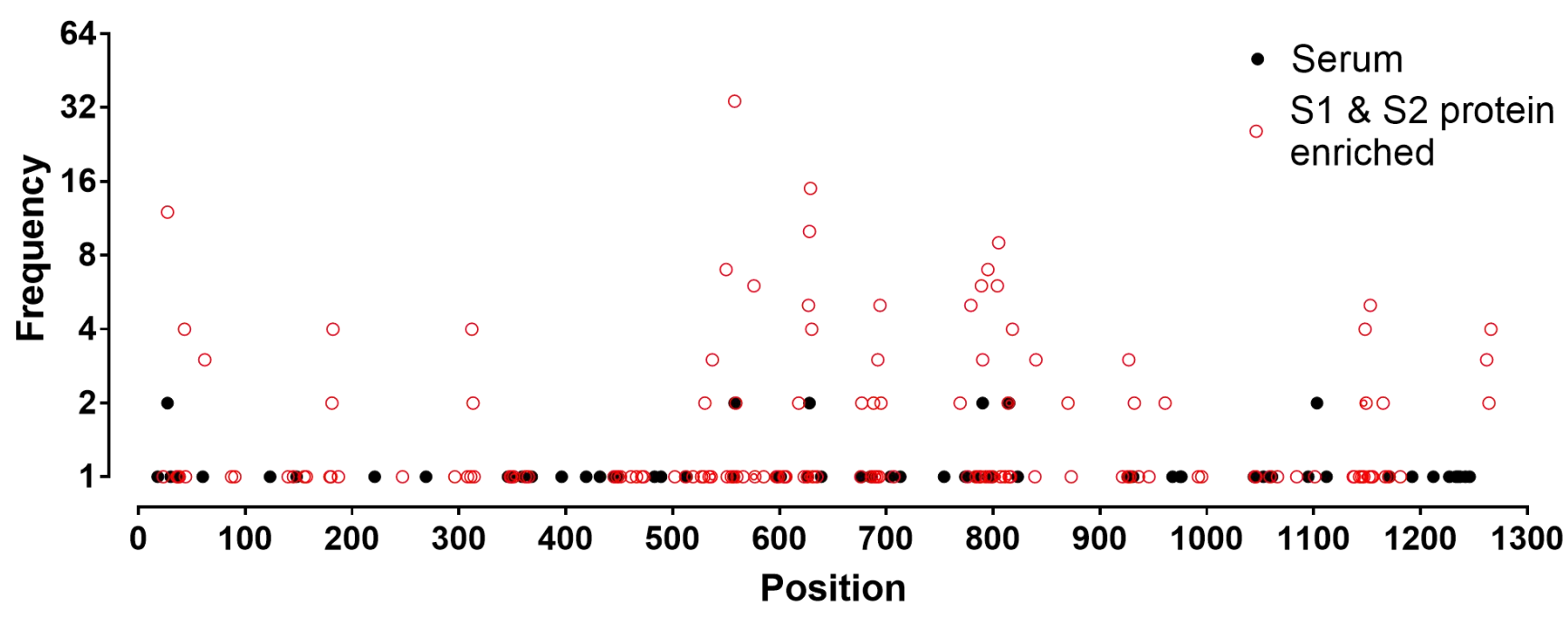




\begin{tabular}{|c|c|c|c|c|}
\hline No. & ID & Sequence & Position & Frequency \\
\hline 1 & Epitope-S1-1 & AYTNSFTR & $27-34$ & 12 \\
\hline 2 & Epitope-S1-2 & FRSSVLHS & $43-50$ & 4 \\
\hline 3 & Epitope-S1-3 & VTWFHAIH & $62-69$ & 3 \\
\hline 4 & Epitope-S1-4 & KQGNFKNL & $182-189$ & 4 \\
\hline 5 & Epitope-S1-5 & IYQTSNFR & $312-319$ & 4 \\
\hline 6 & Epitope-S1-6 & KCVNFNFN & $537-544$ & 3 \\
\hline 7 & Epitope-S1-7 & GVLTESNK & $550-557$ & 7 \\
\hline 8 & Epitope-S1-8 & KFLPFQQF & $558-565$ & 34 \\
\hline 9 & Epitope-S1-9 & VRDPQTLE & $576-583$ & 6 \\
\hline 10 & Epitope-S1-10 & DQLTPTWR & $627-634$ & 5 \\
\hline 11 & Epitope-S1-11 & QLTPTWRV & $628-635$ & 10 \\
\hline 12 & Epitope-S1-12 & LTPTWRVY & $629-636$ & 15 \\
\hline 13 & Epitope-S1-13 & TPTWRVYS & $630-637$ & 4 \\
\hline 14 & Epitope-S2-1 & IIAYTMSL & $692-699$ & 3 \\
\hline 15 & Epitope-S2-2 & AYTMSLGA & $694-701$ & 5 \\
\hline 16 & Epitope-S2-3 & QEVFAQVK & $779-786$ & 5 \\
\hline 17 & Epitope-S2-4 & YKTPPIKD & $789-796$ & 6 \\
\hline 18 & Epitope-S2-5 & KTPPIKDF & $790-797$ & 3 \\
\hline 19 & Epitope-S2-6 & KDFGGFNF & $795-802$ & 7 \\
\hline 20 & Epitope-S2-7 & QILPDPSK & $804-811$ & 7 \\
\hline 21 & Epitope-S2-8 & ILPDPSKP & $805-812$ & 9 \\
\hline 22 & Epitope-S2-9 & IEDLLFNK & $818-825$ & 4 \\
\hline 23 & Epitope-S2-10 & CLGDIAAR & $840-847$ & 3 \\
\hline 24 & Epitope-S2-11 & FNSAIGKI & $927-934$ & 3 \\
\hline 25 & Epitope-S2-12 & FKEELDKY & 1148-1155 & 4 \\
\hline 26 & Epitope-S2-13 & DKYFKNHT & 1153-1160 & 5 \\
\hline 27 & Epitope-S2-14 & EPVLKGVK & $1262-1269$ & 3 \\
\hline 28 & Epitope-S2-15 & KGVKLHYT & 1266-1273 & 4 \\
\hline 29 & Epitope-RBD-1 & RDISTEIY & $466-473$ & 2 \\
\hline
\end{tabular}

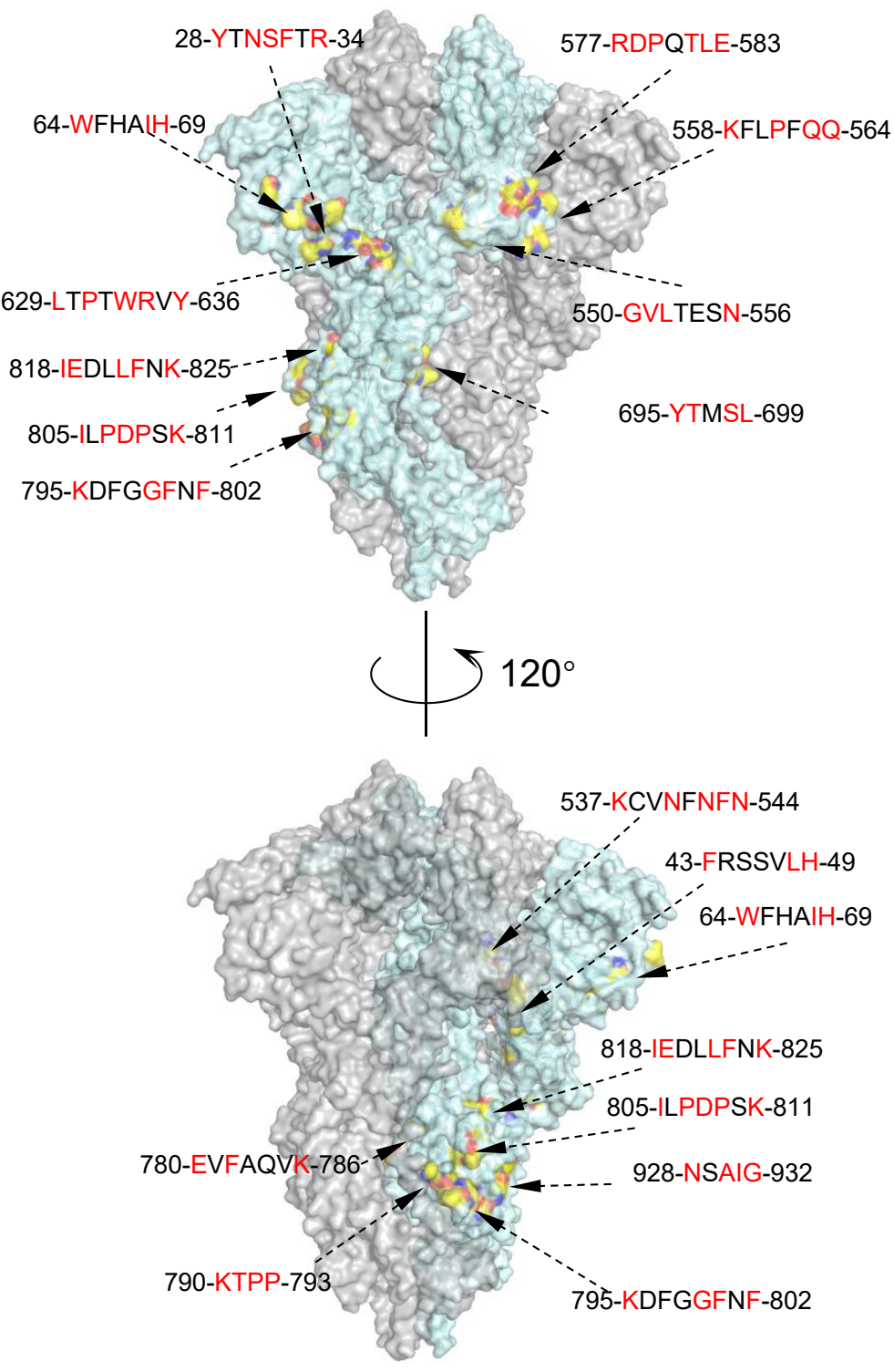


A

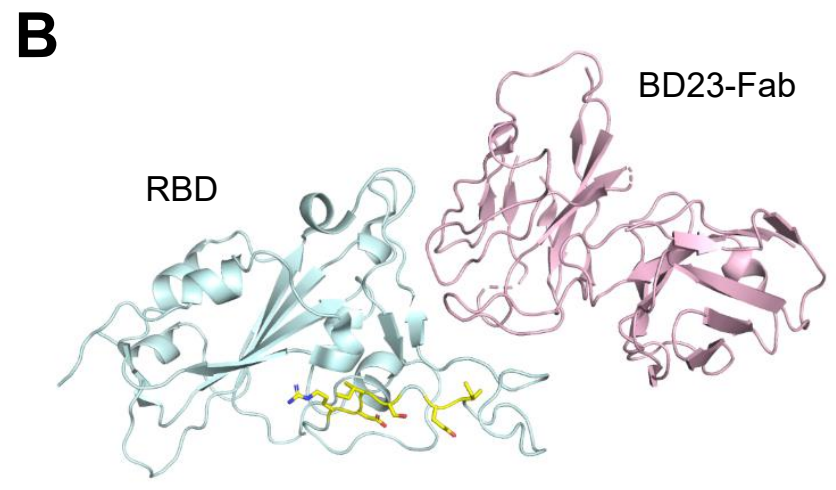

D

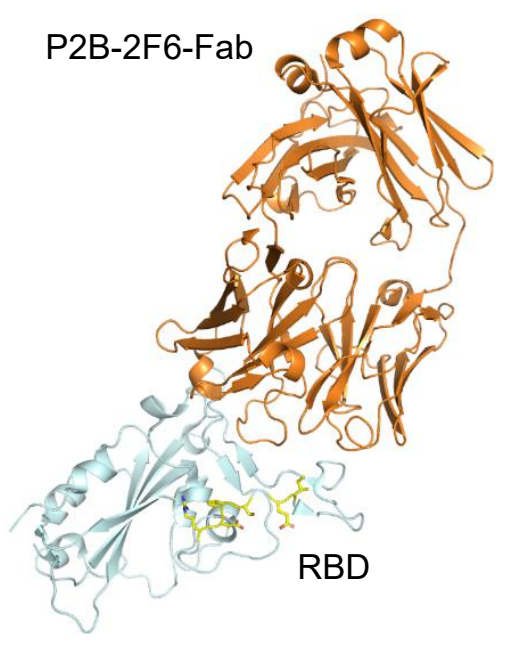

C

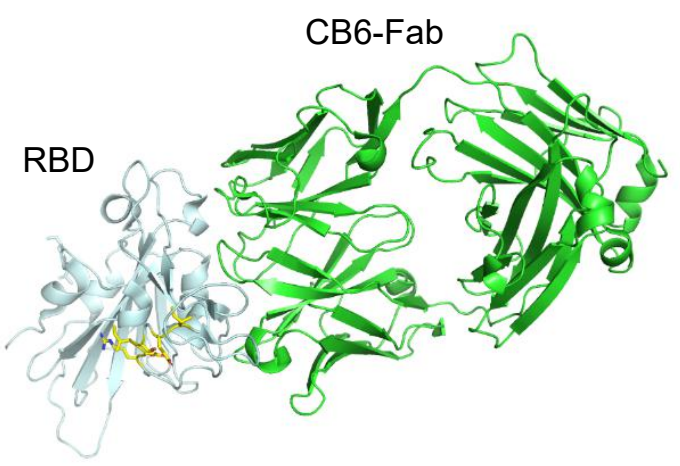

D614G

(36446)

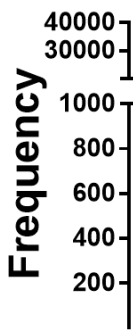

$\odot$

$\mathrm{H} 49 \mathrm{Y}$

D936Y

(493)

P1263L

$\odot$

(306)

$\odot$ (102)

من

$\therefore$ 


\section{Serum-KLFPFQQF}
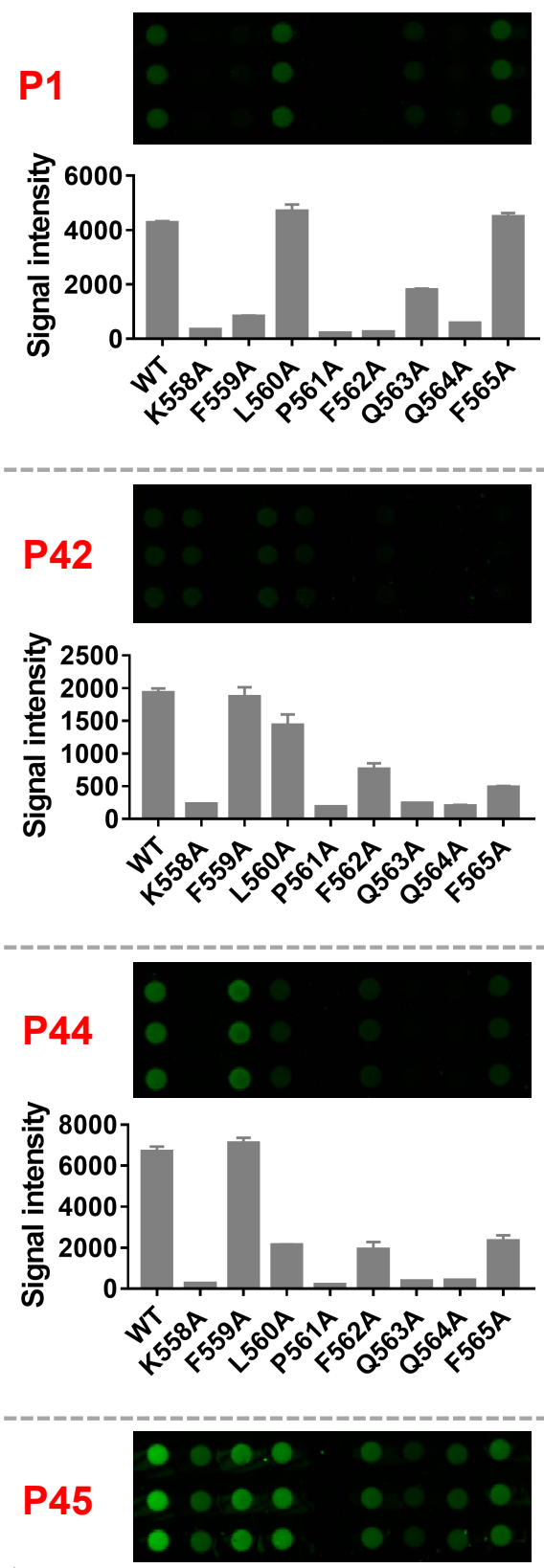

量

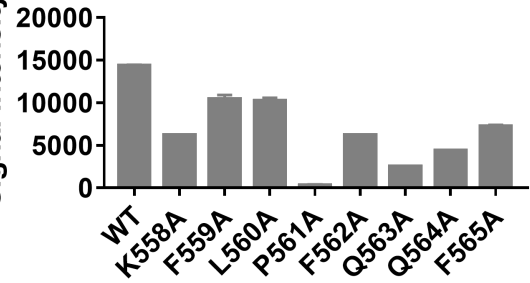

P28

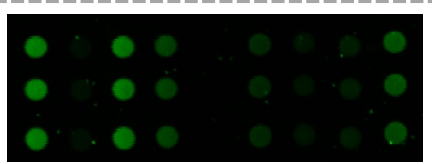


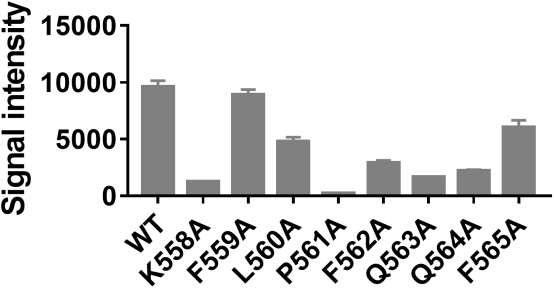

\section{S1 enriched-KLFPFQQF}
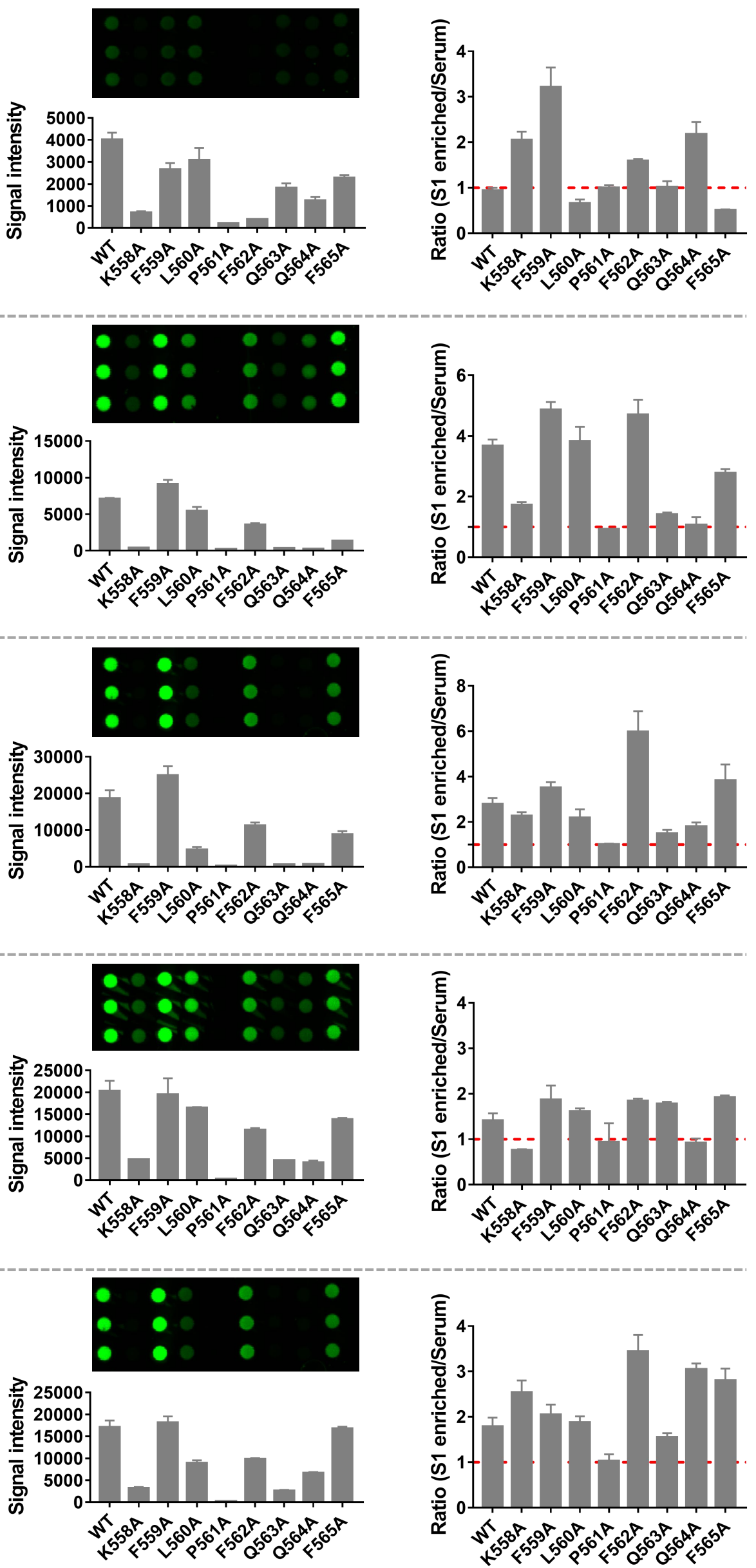


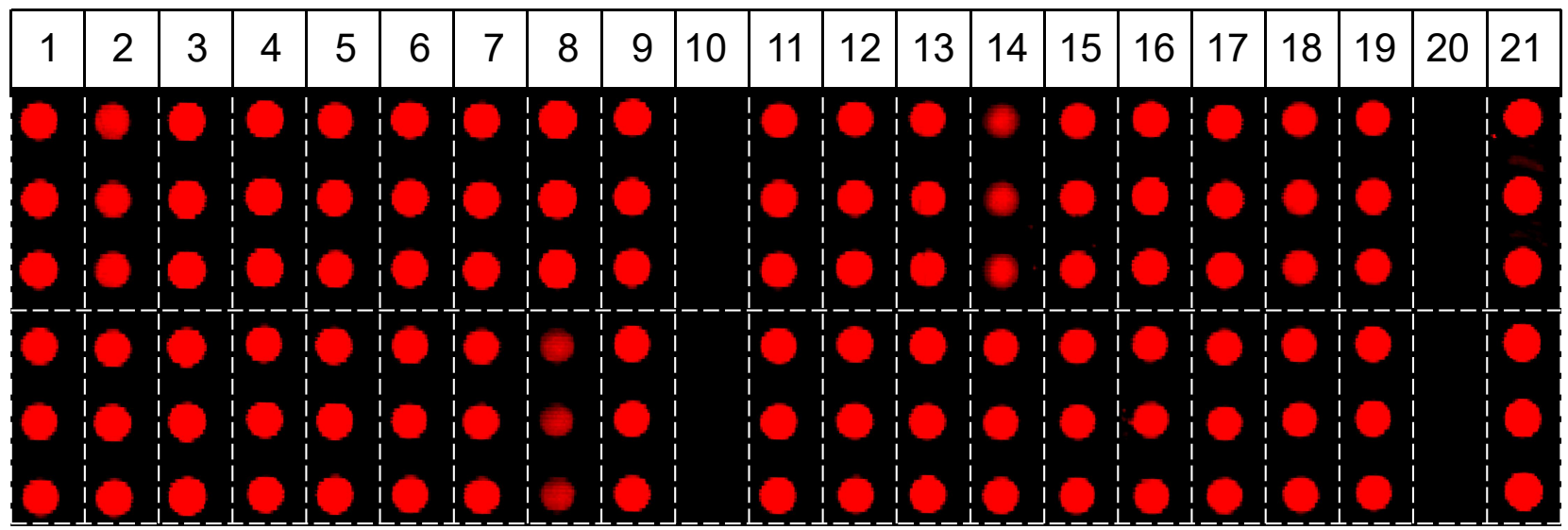

B

\begin{tabular}{|c|c|c|c|c|c|c|c|c|c|c|c|c|c|c|c|c|c|c|c|c|}
\hline & 2 & 3 & 4 & 5 & 6 & 7 & 8 & 9 & 10 & 11 & 12 & 13 & 14 & 15 & 16 & 17 & 18 & 19 & 20 & 21 \\
\hline$\frac{0}{0}$ & 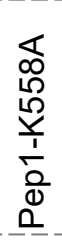 & 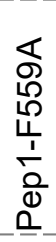 & $\begin{array}{l}\varangle \\
8 \\
6 \\
10 \\
1 \\
1 \\
0 \\
0 \\
0\end{array}$ & $\begin{array}{l}\varangle \\
0 \\
6 \\
0 \\
\frac{1}{1} \\
\frac{1}{0} \\
0 \\
0\end{array}$ & 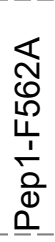 & $\begin{array}{l}\mathbb{1} \\
0 \\
0 \\
0 \\
0 \\
1 \\
\frac{1}{0} \\
0 \\
0\end{array}$ & $\begin{array}{l}\frac{\pi}{f} \\
0 \\
0 \\
0 \\
1 \\
\frac{1}{0} \\
0 \\
0\end{array}$ & $\begin{array}{l}\mathbb{1} \\
10 \\
0 \\
10 \\
\leftarrow 1 \\
1 \\
0 \\
0 \\
0 \\
0\end{array}$ & $\begin{array}{l}\frac{1}{\Phi} \\
\frac{4}{5} \\
0\end{array}$ & 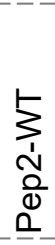 & 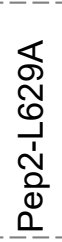 & 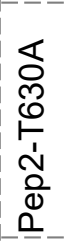 & 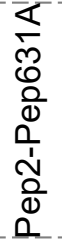 & 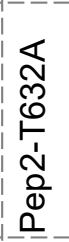 & 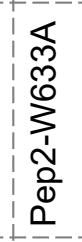 & 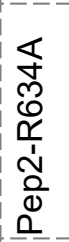 & 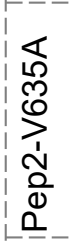 & 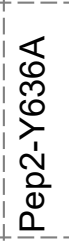 & $\frac{\sum}{1}$ & $\begin{array}{l}0 \\
0 \\
0 \\
1 \\
0 \\
0\end{array}$ \\
\hline 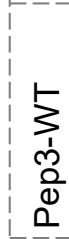 & 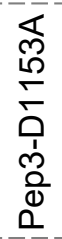 & 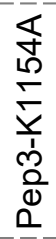 & 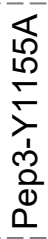 & 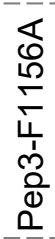 & 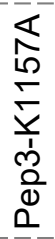 & 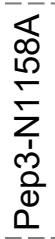 & 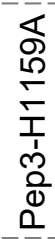 & 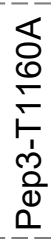 & $\underbrace{\frac{\Phi}{5}}_{0}$ & $\begin{array}{l}5 \\
3 \\
1 \\
0 \\
0 \\
0\end{array}$ & $\begin{array}{l}\nwarrow \\
0 \\
0 \\
0 \\
\frac{1}{1} \\
\vdots \\
0 \\
0 \\
0\end{array}$ & $\begin{array}{l}\mathbb{1} \\
0 \\
0 \\
0 \\
0 \\
\dot{y} \\
o \\
0 \\
0 \\
0\end{array}$ & 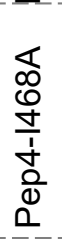 & 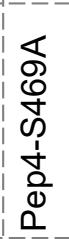 & \begin{tabular}{l}
1 \\
\multirow{2}{0}{$\frac{8}{8}$} \\
0
\end{tabular} & 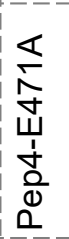 & 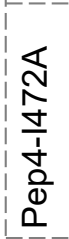 & $\begin{array}{l}\frac{\pi}{m} \\
\stackrel{9}{8} \\
\frac{1}{1} \\
\dot{y} \\
0 \\
0 \\
0\end{array}$ & $\begin{array}{l}0 \\
\frac{0}{1} \\
\frac{1}{1}\end{array}$ & $\begin{array}{l}\infty \\
0 \\
0 \\
1 \\
0 \\
0 \\
0\end{array}$ \\
\hline
\end{tabular}

\begin{tabular}{|c|c|c|c|}
\hline ID & Sequence & ID & Sequence \\
\hline Pep1-WT & KF LPF Q Q F & Pep2-WT & L T P T W R V Y \\
\hline Pep1-K558A & AF L PFQQF & Pep2-L629A & A T P T W R V Y \\
\hline Pep1-F559A & $K A L P F Q Q F$ & Pep2-T630A & L A P T W R V Y \\
\hline Pep1-L560A & KFAPFQQF & Pep2-P631A & L T A T W R V Y \\
\hline Pep1-P561A & KF L AF Q Q F & Pep2-T632A & L T P A W R V Y \\
\hline Pep1-F562A & KF L P A Q Q F & Pep2-W633A & LTP T A R V Y \\
\hline Pep1-Q563A & KF L P F A $\mathrm{F}$ & Pep2-R634A & L TP TW A V Y \\
\hline Pep1-Q564A & KF L P F Q A F & Pep2-V635A & L TP TWRAY \\
\hline Pep1-F565A & KF L P F Q Q A & Pep2-Y636A & L T P T W R V A \\
\hline Pep3-WT & DKY F K H T & Pep4-WT & R D ISTEIY \\
\hline Pep3-D1153A & AKYFKNHT & Pep4-R466A & ADISTEIY \\
\hline Pep3-K1154A & D A Y F K N T & Pep4-D467A & R A I S TEIY \\
\hline Pep3-Y1155A & DKAFKNHT & Pep4-|468A & RDASTEIY \\
\hline Pep3-F1156A & DKYAKNHT & Pep4-S469A & RDIATEIY \\
\hline Pep3-K1157A & DKY F A N H & Pep4-T470A & RDISAEIY \\
\hline Pep3-N1158A & DKYFKAHT & Pep4-E471A & RDISTAIY \\
\hline Pep3-H1159A & DKYFKNAT & Pep4-|472A & RDISTEAY \\
\hline Pep3-T1160A & DKYFKNHA & Pep4-Y4T3A & R D ISTEIA \\
\hline
\end{tabular}




\section{Table S1. Serum samples tested in this study}

\begin{tabular}{|c|c|c|}
\hline \multicolumn{2}{|c|}{ COVID-19 patients } & \multirow{2}{*}{$\begin{array}{c}n=55 \\
27\end{array}$} \\
\hline & Male & \\
\hline Gender & Female & 28 \\
\hline \multirow{3}{*}{ Age } & Mean \pm s.d. & $41.5 \pm 14.8$ \\
\hline & $<60$ & 48 \\
\hline & $\geq 60$ & 7 \\
\hline \multirow{2}{*}{ Severity } & Mild & 55 \\
\hline & Severe and critical & 0 \\
\hline \multirow{2}{*}{ Outcome } & Recovered & 55 \\
\hline & Death & 0 \\
\hline \multicolumn{2}{|c|}{ Days after symptom onset for sampling } & $27.5 \pm 7.7$ \\
\hline \multicolumn{2}{|c|}{ Control group } & $n=25$ \\
\hline \multicolumn{2}{|c|}{ Healthy controls } & 5 \\
\hline \multicolumn{2}{|c|}{ Lung cancer } & 20 \\
\hline \multirow{2}{*}{ Gender } & Male & 15 \\
\hline & Female & 10 \\
\hline \multirow{3}{*}{ Age } & Mean \pm s.d. & $51.7 \pm 12.7$ \\
\hline & $<60$ & 18 \\
\hline & $\geq 60$ & 7 \\
\hline
\end{tabular}



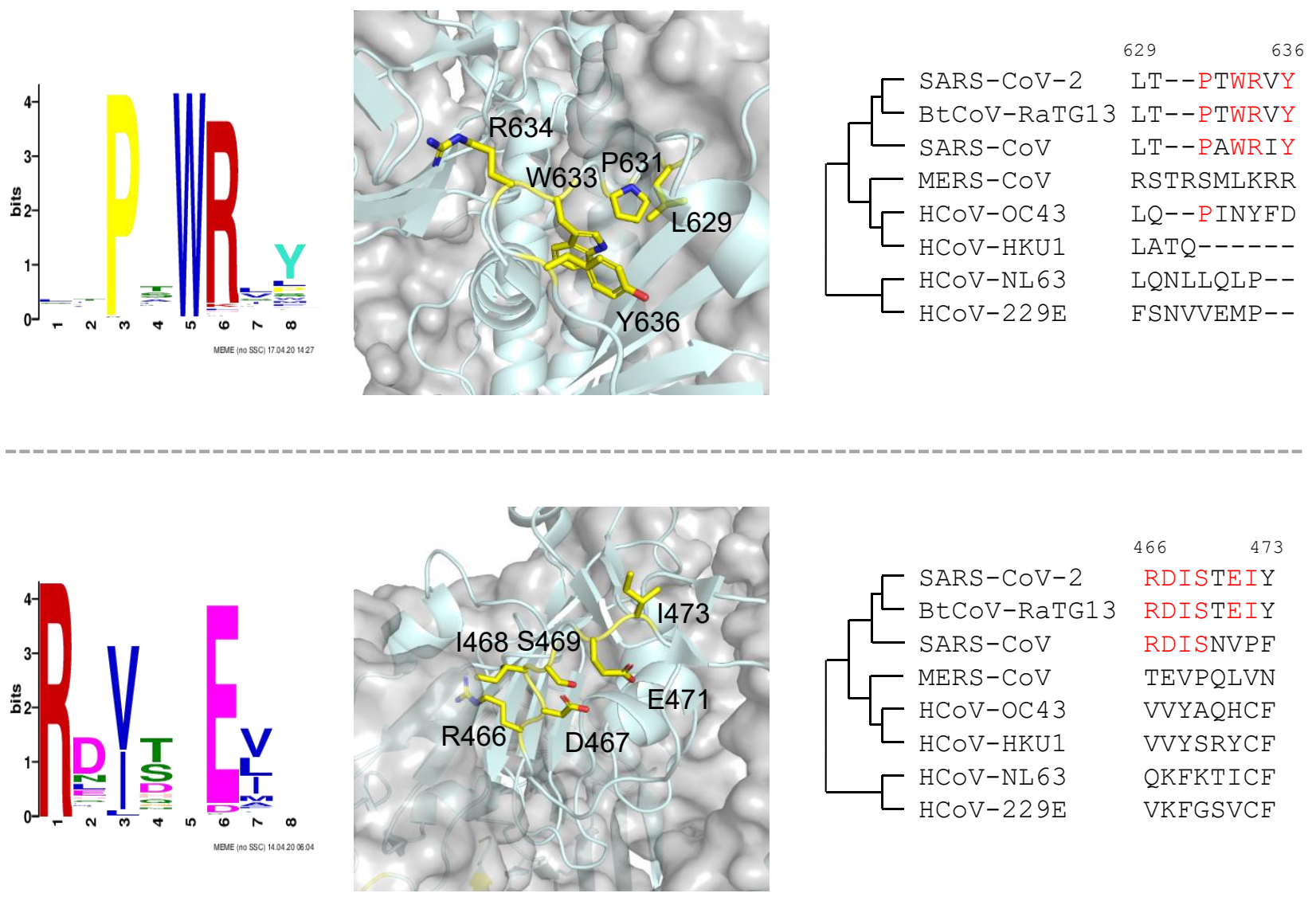
er review) is the author/tunder, who has granted medRxiv a license to display the preprint in perpetui It is made available under a CC-BY-NC-ND 4.0 International license .
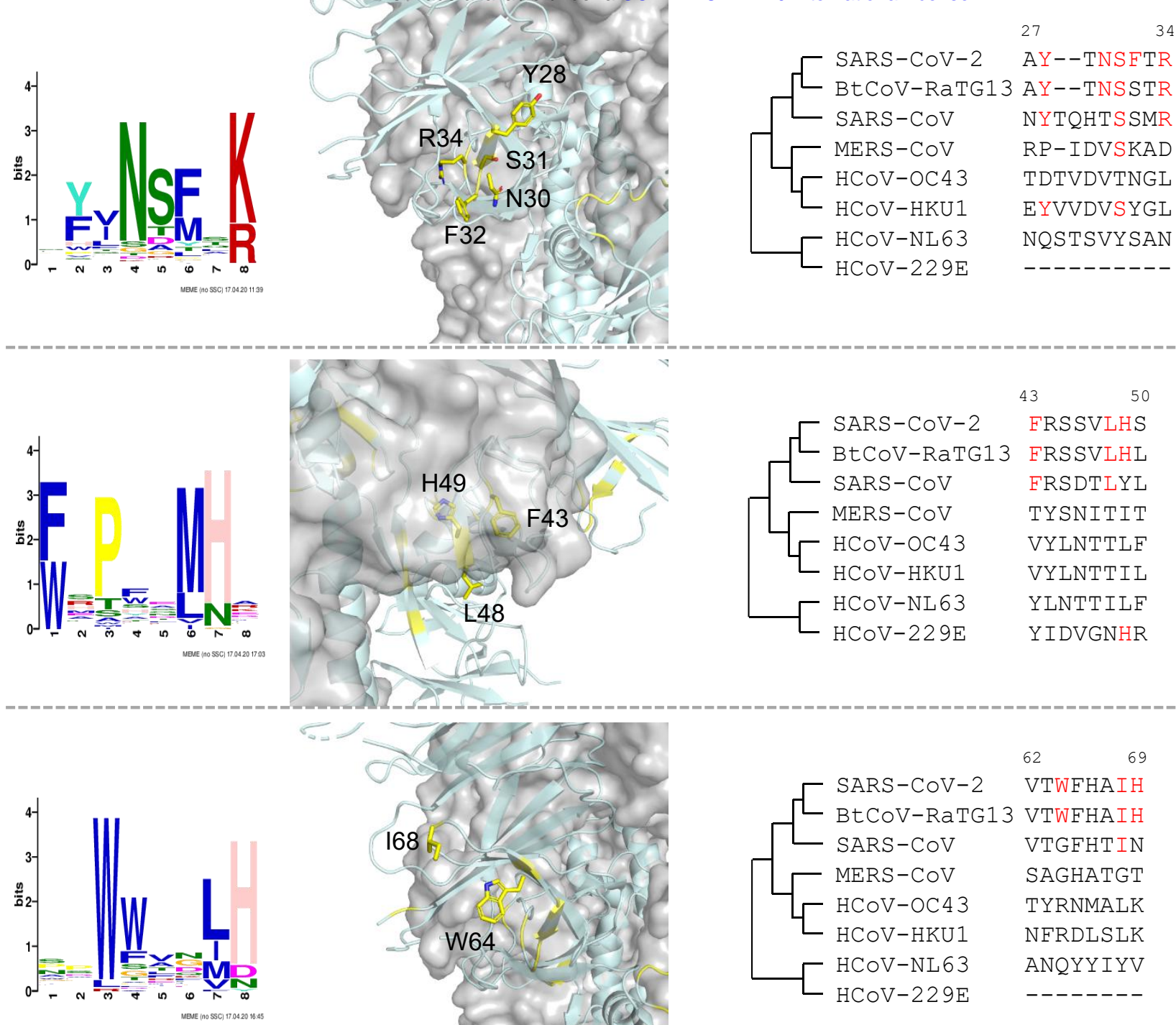

43
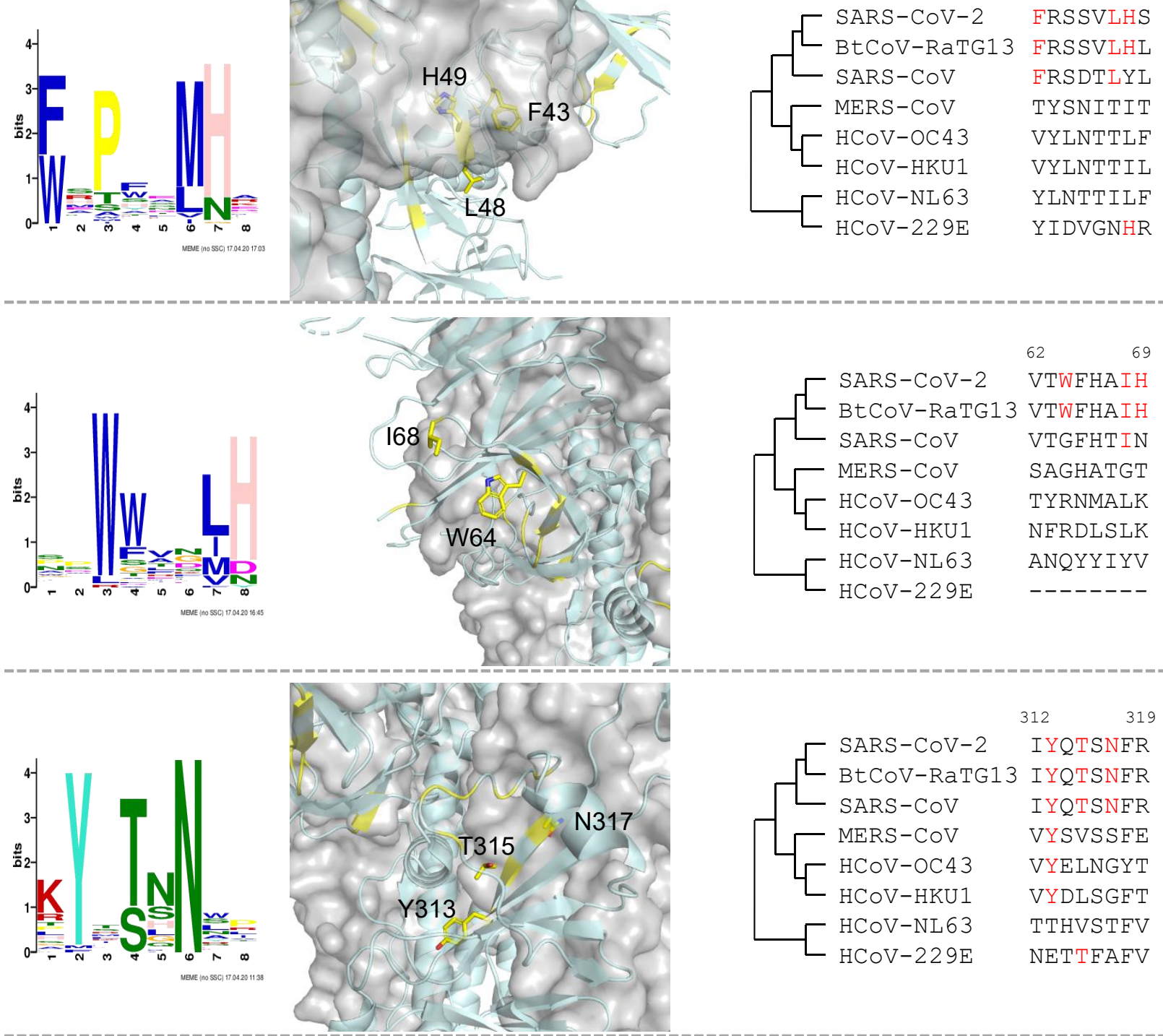

$312 \quad 319$
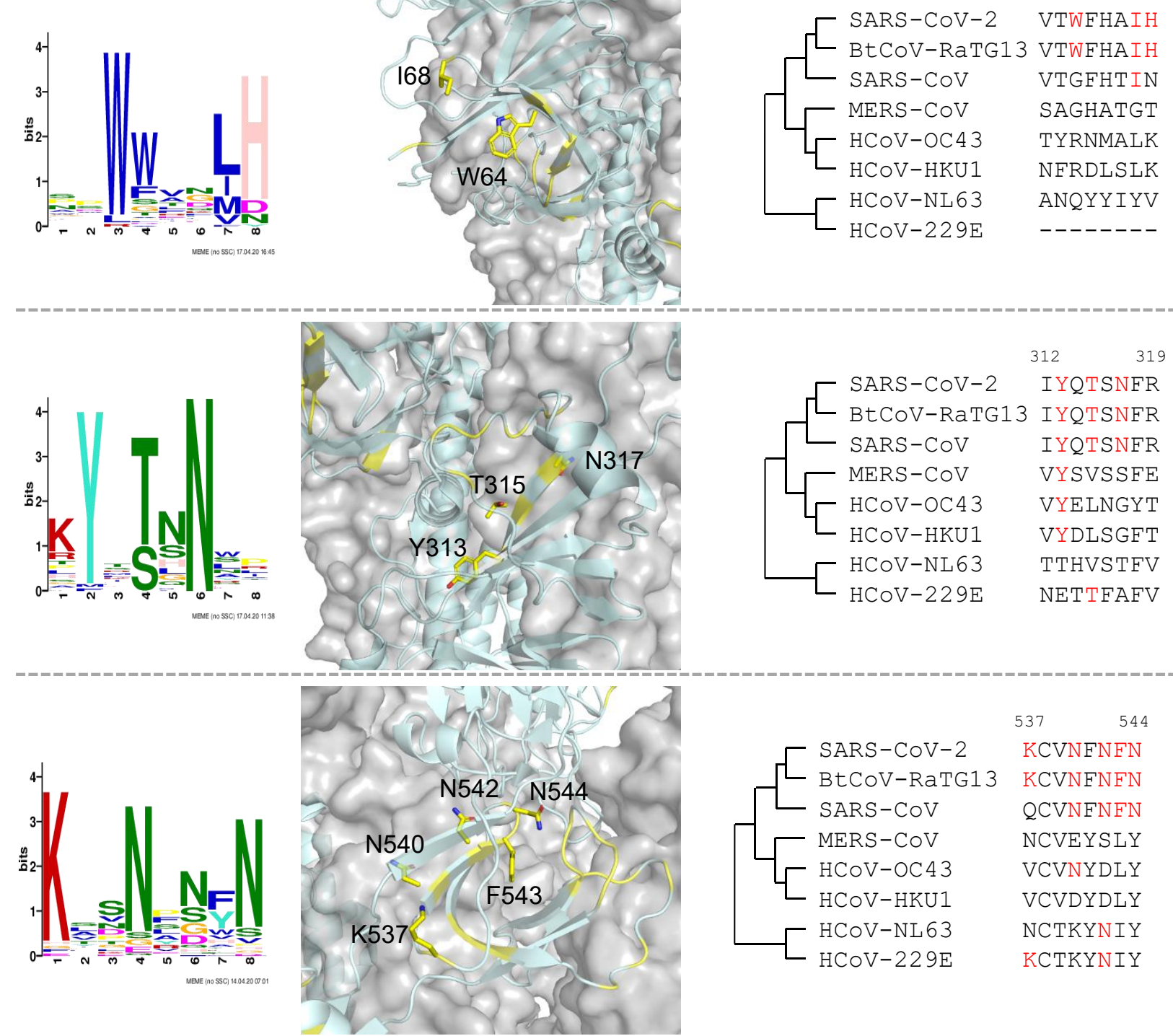
(which was not certitied by peer review) is the author/tunder, who has granted medRxiv a license to display the preprint in perpetult It is made available under a CC-BY-NC-ND 4.0 International license.
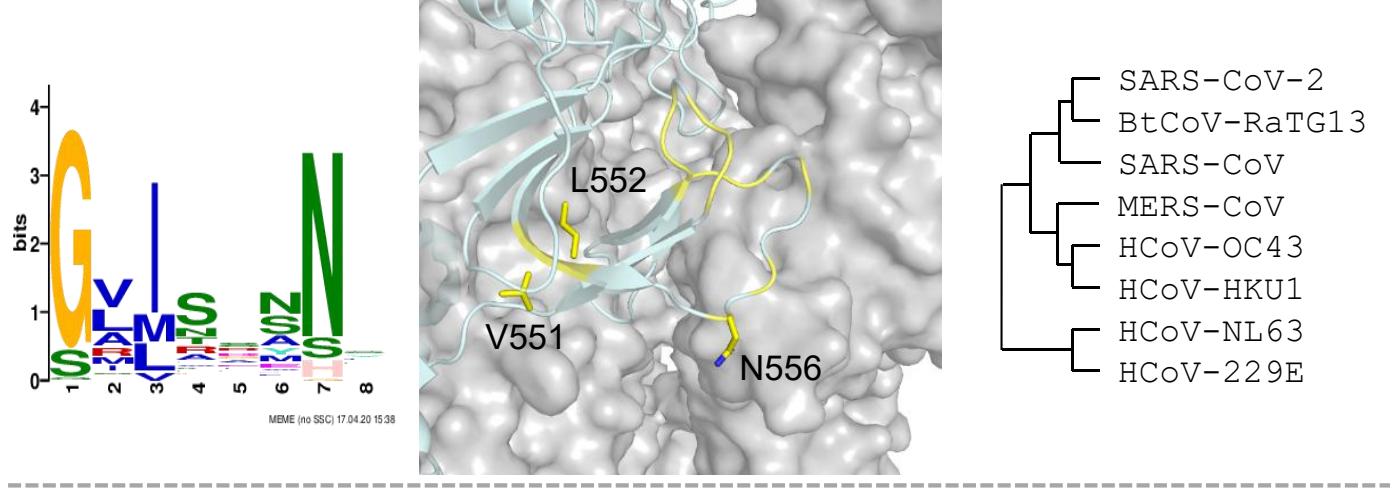

$550 \quad 557$

GVLTESNK

GVLTESNK

GVLTPSSK

GVFQNCTA

GIFVEVNA

GIFKEVSA

GVIRSSNQ

GIIRISND
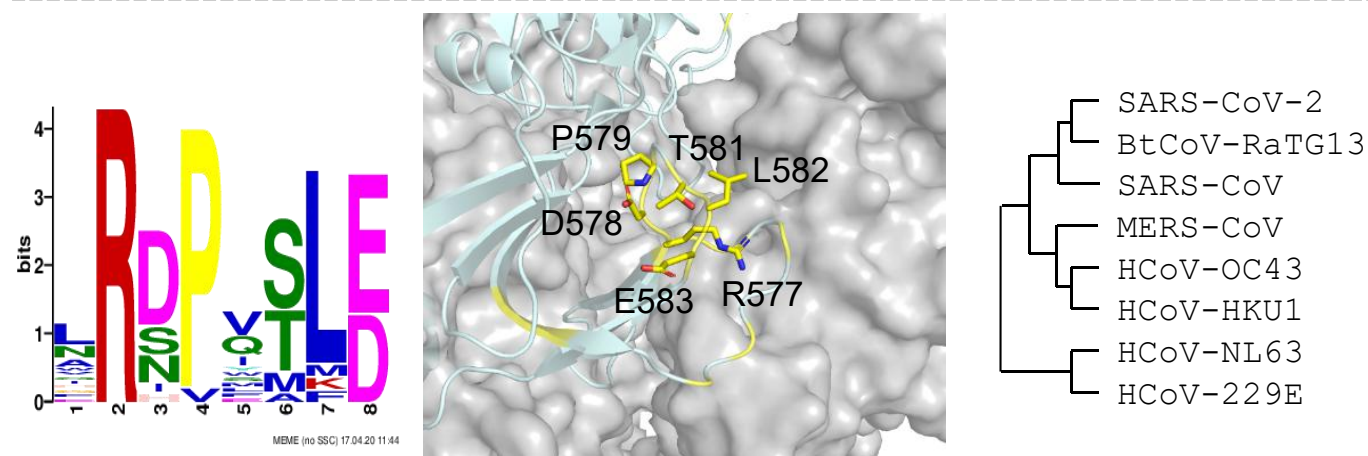

576

583

VRDPQTLE

VRDPQTLE

VRDPKTSE

YSD--DGN

FRDYIINR

FKDFVTNK

FKNVSTGN

FKDVTNGT
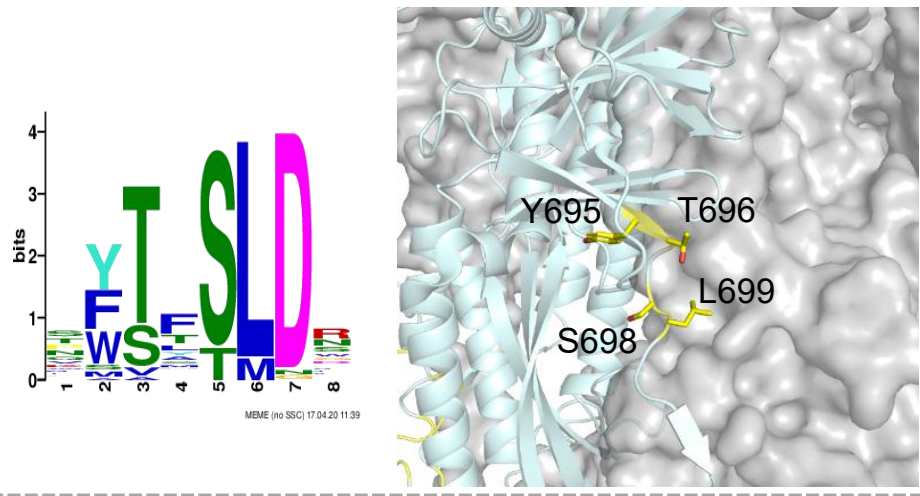

694

701

AYTMSLGA

- SARS-COV-2

AYTMSLGA

— BtCoV-RaTG13

AYTMSLGA

- SARS-COV

AFNHPIQV

- MERS-COV

PETVNS-V

- $\mathrm{HCOV}-\mathrm{OC} 43$

PFNVSF-V

- HCOV-NL63

- - - - - -

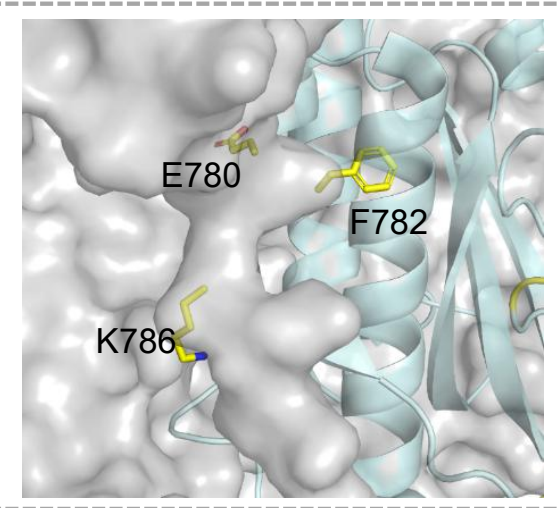

$779 \quad 786$
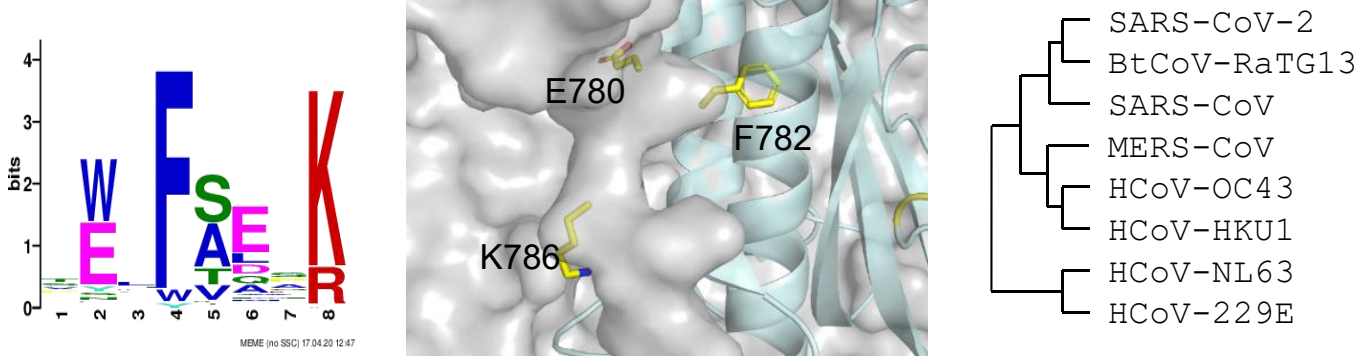

QEVEAQVK

QEVFAQVK

REVFAQVK

RNLFASVK

LQVANSLM

LHVADTLM

VSSMLTED

VSEMLTED

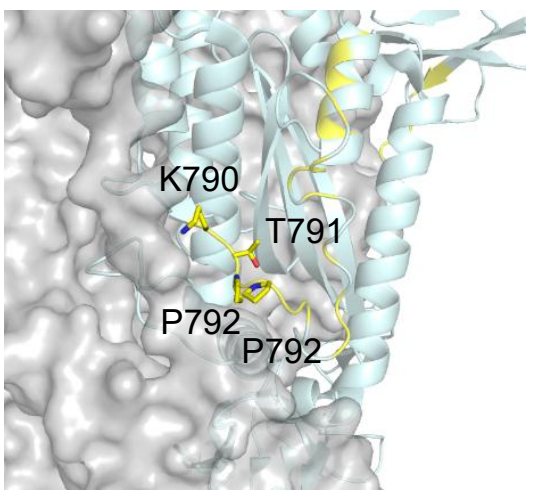

789

796

YKTPPIKD

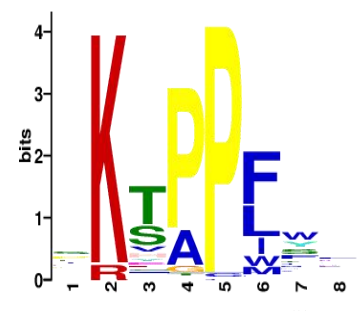

Qi et al., Table S4 

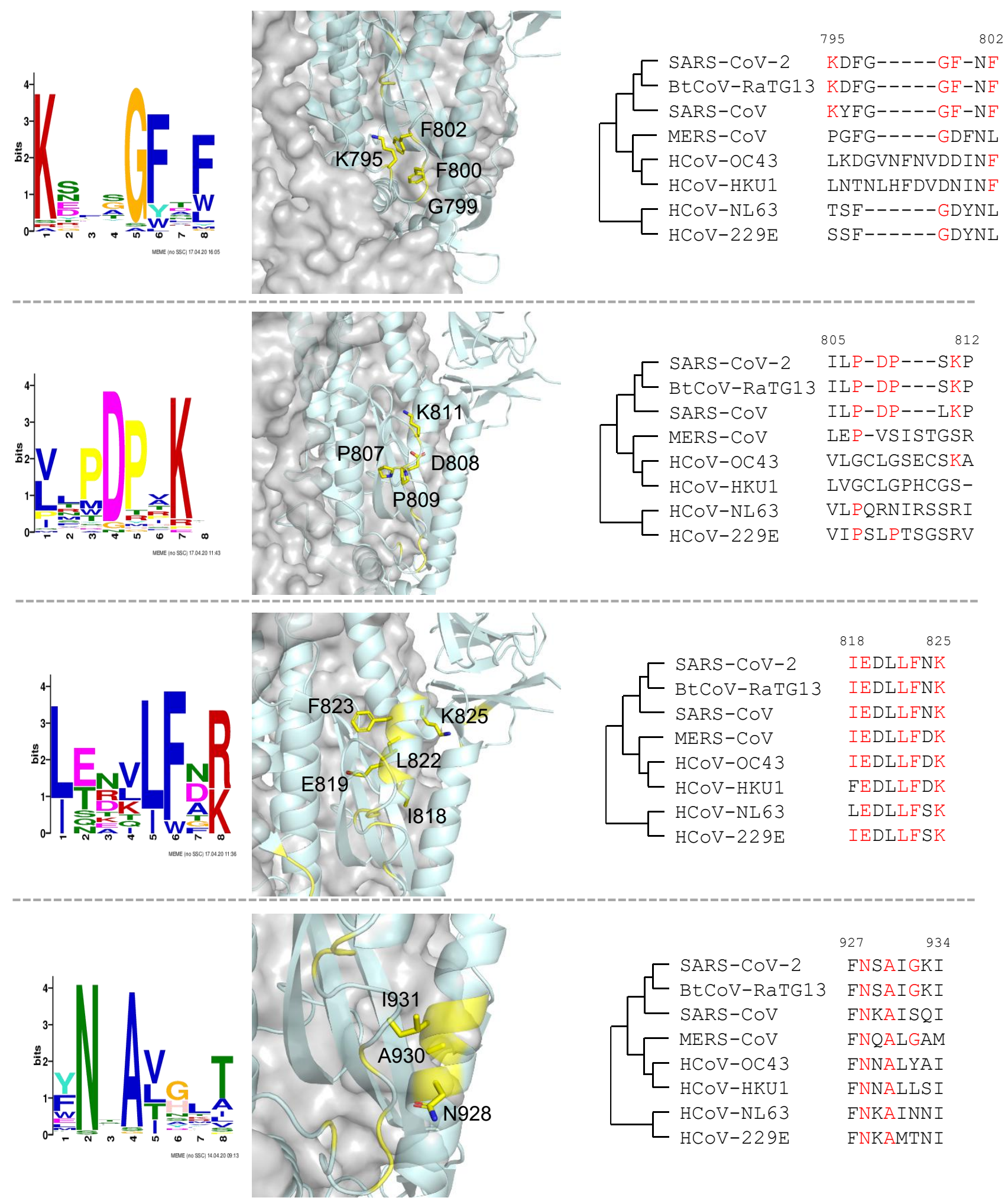

$927 \quad 934$

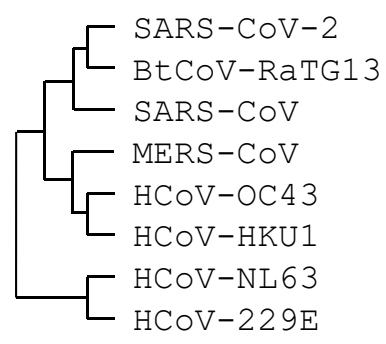

FNSAIGKI

FNSAIGKI

FNKAISQI

FNQALGAM

FNNALYAI

FNNALLSI

FNKAINNI

FNKAMTNI

\section{Qi et al., Table S4}


eer review) Is the author/tunder, who has granted medRxIV a license to display the preprint in perpetuI
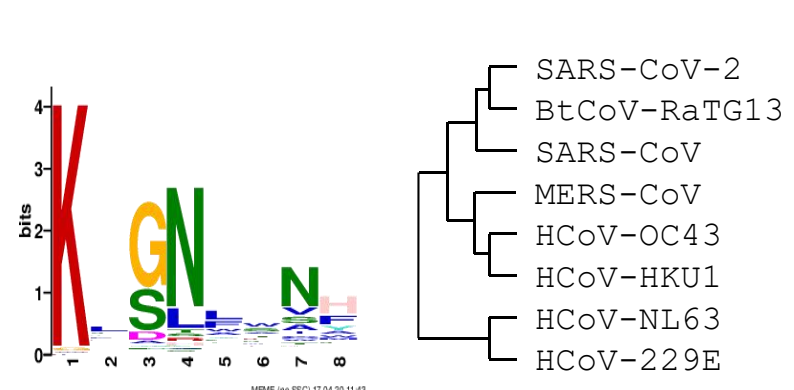

$182 \quad 189$

K--QGNFKNL

K--QGNFKNL

K--SGNFKHL

LNSFKEYFNL

G--VVSCLYK

S--EPLCLFK

GRIPNGFPFN

GYIPSDFAFN
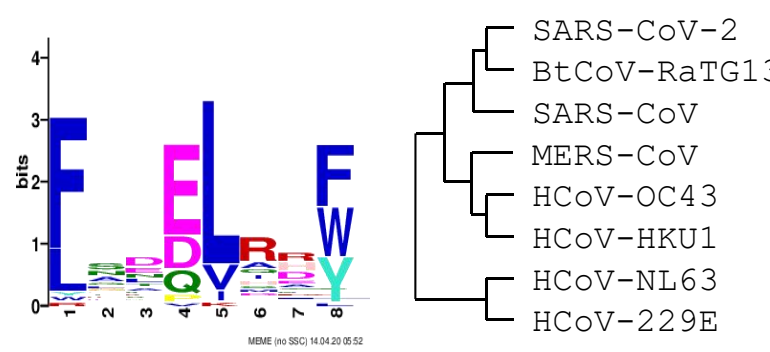

1148

1155

FKEELDKY

FKEELDKY

FKEELDKY

FQDELDEF

FKEELDQW

FESELSHW

VNKTLQEF

VNKTLQEL
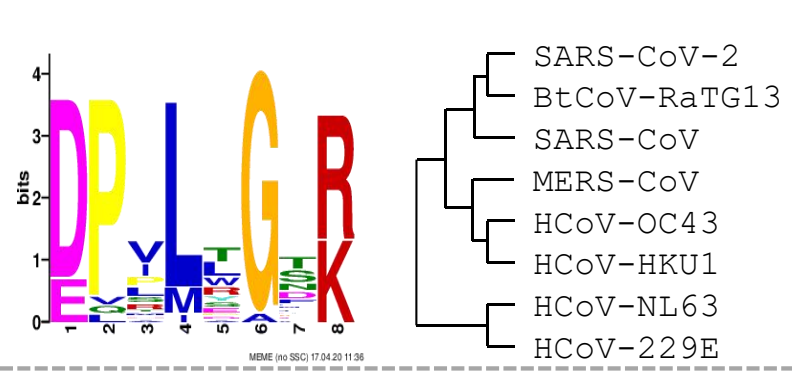

1262

1269

EPVLKGVK

EPVLKGVK

EPVLKGVK

LEPHKVHV

ELVIKTSH

DEVIKTSH

LPYYEFEK

LPYYDVEK

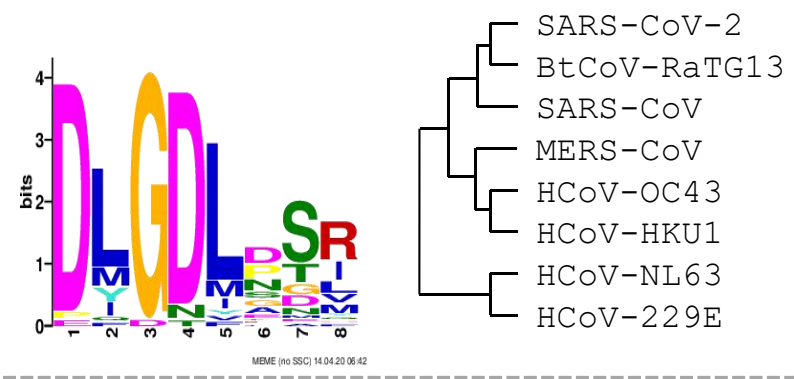

840

CLGD--IAAR

CLGD--IAAR

CLGD--INAR

CMQQGPASAR

CTGG--AEIR

CTGG--SEIR

CTKG--LSIA

CTKG--LSIA
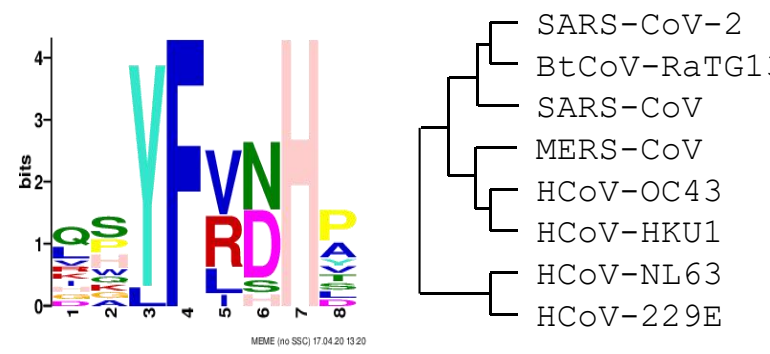

1153

DKYFKNHT

DKYFKNHT

DKYFKNHT

DEFFKNVS

DQWEKNQT

SHWEKNQT

QEFAQNLP

QELSYKLP
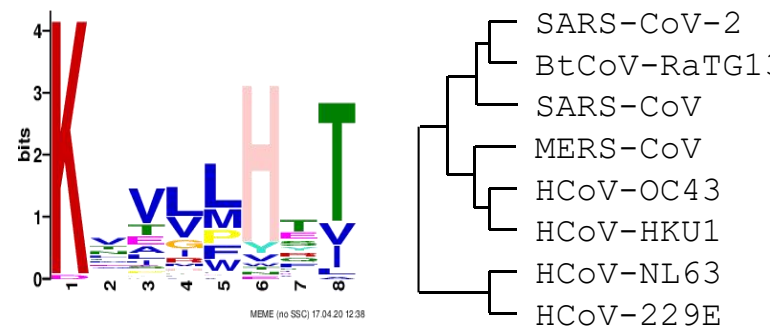

1266

1273

KGVKLHYT

KGVKLHYT

KGVKLHYT

KVHVH---

KTSHDD--

KTSHDD--

EFEKVHVQ

DVEKIHIQ

\section{Qi et al., Table S4}

